\title{
Housing Values and the Residential Settlement of Migrants: Zooming in on Neighbourhoods in Italian Provincial Capitals
}

\author{
Sona Kalantaryan ${ }^{1}$ D $\cdot$ Alfredo Alessandrini $^{1}$
}

Accepted: 12 September 2020 / Published online: 7 November 2020

(c) The Author(s) 2020

\begin{abstract}
This study looks at the relationship between housing values (prices and rents) and the residential settlement of migrants in different neighbourhoods in Italian provincial capitals. We exploit here the high spatial resolution dataset on the settlement of migrants developed within the Data for Integration (D4I) project. The D4I information on resident population characteristics was merged with a dataset on housing values for civilian and economic residential units using boundaries defined by local housing market characteristics. The results suggest that: (1) more diverse neighbourhoods are also those with relatively lower housing values; (2) the relationship between housing values and the concentration of migrants is non-linear; and (3) the sign and significance of the association varies significantly depending on the origin of migrants.
\end{abstract}

Keywords Migration · Residential segregation · Diversity · Housing market · Italy

\section{Introduction}

The last decades have seen intense migration towards European countries, including Italy - the subject of this study. Many consider migration to be a solution to several demographic issues that Europe has been facing: for instance aging populations and declining birth rates. The interest in the causes and possible consequences of migration has generated an impressive body of economic and sociological writing. The prevailing part of the economic literature on immigration is focused on its impact on labour market outcomes and hence the income of the residing population. However,

Electronic supplementary material The online version of this article (https://doi.org/10.1007/s4098 0-020-00068-1) contains supplementary material, which is available to authorized users.

Sona Kalantaryan

Sona.Kalantaryan@ec.europa.eu

1 European Commission Joint Research Centre (JRC), Ispra, Italy 
the labour market is not the only channel through which migrants can influence the income and wealth of natives. Migrant residential settlement patterns can also affect the wealth of the native population through the impact that they have on house prices and rents. ${ }^{1}$ While the causal impact of migration on housing market dynamics is beyond the scope of this study, we shed some light on the relationship between the settlement of various groups of migrants and housing values (prices and rents) drawing on the example of Italian provincial capitals.

The inflow of migrants creates additional demand for residential units. Housing is considered to be a non-tradable good with relatively inelastic supply, at least over the short term. This means that qualitative and quantitative changes in housing demand, caused by intensive immigration, may be translated into changes in local house prices and rents. However, the direction of these changes is difficult to predict due to the complexity of housing markets and numerous factors to be considered: local economic conditions; the demographic composition of the immigrant flow; macroeconomic conditions and expectations; institutional factors affecting the elasticity of the supply of listed residential units in the short term and new dwellings in the longer term; as well as the way the native-born react to immigration (Cochrane and Poot 2020). Usually, migrants are not evenly distributed across a destination country and tend to settle in urban areas where their communities are already established and Italy is no exception to this rule (Jayet et al. 2010). Then within cities, the concentration of migrants varies significantly across neighbourhoods (Boeri et al. 2012; Natale et al. 2018a). Moreover, due to their relatively low income levels migrants gravitate towards relatively cheap housing units, are forced to live in overcrowded flats (Bonifazi and Sabatino 2003; Barban and Dalla-Zuanna 2010). ${ }^{2}$ The uneven distribution of migrants across a given country will likely have an uneven impact on the housing market (segments, neighbourhoods).

There are several reasons for choosing the Italian housing market as the subject of this empirical study. First, the country drastically changed its role in the global migration process. Italy was traditionally considered to be a donor country. However, within two decades the number of individuals born outside the country increased drastically reaching 5.8 million in $2011 .^{3}$ Ten percent of its population is now foreign born. Taking into account demographic and economic developments in African countries, one can predict with high certainty that the stock of migrants in Italy will continue to grow (Natale et al. 2018b). Second, migrants are

\footnotetext{
1 Italian households have strong preferences towards housing wealth (Brandolini et al. 2004; Faiella and Neri 2004) and owner occupation (Paiella 2001; Di Addario 2002). In 2011 the house ownership rate in Italy stood at $78 \%$ for natives and $38 \%$ for the foreign-born (Eurostat, Distribution of population by broad group of country of birth and tenure status (population aged 18 and over) [ilc_lvps16]).

${ }^{2}$ In 2011, the overcrowding rate among foreign-born population in Italy was $40.2 \%$ which is twice as high as figures observed for natives (Eurostat, Overcrowding rate by age, sex and broad group of country of birth (total population aged 18 and over) [ilc_lvho16]).

3 Population on 1 January by age, sex and broad group of country of birth [migr_pop4ctb]. Eurostat. These figures do not account for a sizable stock of irregular migrants who influence the housing market as well. The estimated size of the irregular foreign resident population in Italy in 2008 was (from 279,000 to) 461,000 (Kovacheva and Vogel 2009). According to other studies it reached 651,000 in the same year (Blangiardo 2006, 2007, 2008; Fasani 2010).
} 
not evenly distributed across and within Italian municipalities (Boeri et al. 2012; Jayet et al. 2010), which allows for a study of variations in the concentration of migration in relationship to housing values. Third, the Italian housing market is relatively deregulated; hence changes in supply and demand are readily reflected in house prices. Unlike some northern European countries with pseudo-housing markets, such as Belgium, Denmark and the Netherlands, where immigrants can rely on state support by receiving public housing, Italy has a housing market with minimal state intervention (Cuerpo et al. 2014; Elsinga and Wassenberg 2014; Scanlon et al. 2015). The liberalization of rents declared in the late 1990s caused significant changes in the housing market in Italy; from 1999 until 2006 rental prices in cities with populations of more than 25,000 increased by around $112 \%$ (Censis 2007). During the same period, the already insufficient stock of public housing in Italy shrank further, due to the sale of public housing, which was not compensated for by the building of new residential units (Pozzo 2002).

We investigate the relationship between the presence of migrants and housing values in the neighbourhoods of Italian provincial capitals against a backdrop of: (a) the intense immigration of last decades; (b) the uneven spatial distribution of migrants between and within municipalities; (c) an increase in demand and limited supply for housing suited to migrant characteristics; and (d) a largely unregulated housing market. The study builds on the information provided by the Data for Integration project which was used to build a dataset of resident population composition by country of origin (birth) in the neighbourhoods of Italian provincial capitals in 2011. Thanks to high spatial resolution information on population it was possible to obtain the characteristics of residents within the boundaries defined by the dataset on housing values (micro areas) provided by the Observatory of Real Estate Markets of the Italian fiscal authority.

This study sheds light on the relationship between the presence of migrants and housing values in the neighbourhoods of Italian provincial capitals and contributes to the existing literature in the following way. First, taking into account the importance of housing-related expenses and income in households' budgets and the high rate of homeownership in Italy, the study improves our understanding of the effect that immigration might have on the real income and the wealth of the Italian population. Second, the obtained results are important for understanding the impact of immigration on the dynamics of housing values in various segments of the Italian housing market and in destination countries in general. The obtained results suggest a non-linear relationship between the concentration of migrants and housing values. Moreover, more diverse neighbourhoods are associated with lower house prices and rents. Though more analysis is warranted for clarifying the causes and consequences of ongoing residential segregation in Italy, the study suggests that natives see the presence of immigrants in the area (neighbourhood) as a negative amenity. The obtained results may help to evaluate the tendencies and the extent of spatial segregation in urban areas in Italy; hence, 
they may provide insights for policymakers involved in designing measures for the integration of immigrants residing in urban areas. ${ }^{4}$

The rest of the paper is organized in the following way. Section 2 provides an overview of the relevant literature. Section 3 presents the empirical strategy used to understand the relationship between migration and housing values and describes the data. Section 4 reports and discusses the results. Section 5, then, concludes the study.

\section{Related Literature}

Research on the impact of immigration on house prices and rents is mostly focused on more traditional destinations such as the United States, Canada and New Zealand. ${ }^{5}$ Cochrane and Poot (2020) provide a survey of international evidence regarding the impact of immigration on local housing markets and suggest that immigration leads to higher house prices and rents, and lower housing affordability. However, while the theoretical framework developed by the authors highlights the complexity of the housing market, the evidence from eight countries and the metaanalysis indicate that there is a large variance in estimated effects due to the time frame and the spatial scale of the analysis, and local economic and institutional factors. At the country level migrants, as additional consumers, generate extra demand for residential units. However, the overall increase affects various segments of the housing market differently. The dynamics of housing values at the provincial or regional level depends on the relationship between natives and migrants in the production process. If natives and migrants are complementary in the production process, then both groups will be attracted to the same regions with a consequent increase in house prices and rents due to an increase in local housing demand. If the two groups are substitutes in the production process, then natives may avoid the regions where migrants settle in large numbers, becoming wary of competition on the local labour market (Filer 1992). An earlier study empirically examines the impact of immigration on the dynamics of house prices across the Italian provinces. Using the number of valid residence permits as a measure of immigration stock and the self-reported housing values from the Survey of Households Income Wealth in Italy from 1996 till 2007 Kalantaryan (2013) demonstrates that the increase in the concentration of immigrants in the Italian provinces has a positive but declining effect on average house prices The complementarity of migrants and natives in the labour markets seems important in explaining the impact migrants have on the dynamics of housing values at the regional rather than at the neighbourhood level.

\footnotetext{
${ }^{4}$ Boeri et al. (2012) demonstrate that migrants themselves are affected by segregation. Migrants residing in neighbourhoods with a high concentration of foreign nationals are less likely to be employed compared to similar migrants who reside in less segregated areas.

${ }^{5}$ See Table 1 in appendix 1 for the summary of results of selected studies on the housing market impact of immigration.
} 
The impact of migrants on housing values at the neighbourhood level depends largely on the attitude of established residents. If natives consider the physical presence of migrants in the area to be a negative amenity, they may prefer to leave or at least not to settle in neighbourhoods where migrants have a strong presence. The meta-analysis conducted by Larkin et al. (2018) links 474 comparable estimates from 45 econometric studies, covering 14 developed countries with the World Value Survey data on attitudes towards migrants. The study demonstrates that in countries with a high percentage of respondents who are reluctant to have immigrants as neighbours house price increase is more limited.

Are migrants perceived as a negative or positive local amenity in Italy? A growing body of research on public opinion towards migrants indicates that in Italy current migration is frequently perceived negatively by natives (Barbulescu and Beaudonnet 2014; Panichella and Ambrosini 2018). The results of the European Social Survey conducted in Italy in 2002 suggest that most Italians are not willing to live in an area populated by ethnic minority groups (55\%). ${ }^{6}$ According to the Eurobarometer survey, three-quarters of Italian respondents have either fairly negative (42\%) or very negative feelings towards immigration from outside EU. The formation of this attitude is affected by numerous factors including competition in the local labour market (Kenneth and Slaughter 2001; Mayda 2006). ${ }^{7}$ Empirical research suggests that migrants do not have a negative impact on the labour market outcome of the native-born population in Italy (Del Boca and Venturini 2005; Venturini and Villosio 2004; Staffolani and Valentini 2010; Romiti 2011). The conflict between the economic acceptance and political rejection of migrants by locals in Italy has been described by Ambrosini (2013) as a dilemma "reconciling interests and feelings, head and hearts, individual and communities". This pushes us to look for the drivers of negative attitudes beyond the labour market. The reluctance to live in migrant areas might be due to a widespread opinion that migrants contribute less to local budgets and receive benefits more frequently than natives-something not supported by relevant studies (Huber and Oberdabernig 2016; Pellizzari 2013). The negative attitude might also be motivated by the false perception that migrants generate crime in the areas in which they live (Bianchi et al. 2012; Bonifazi and Sabatino 2003). ${ }^{8}$ Families with school-age children may be unwilling to send their children to schools in mixed neighbourhoods due to actual or perceived changes in the quality of schools (Bayer et al. 2007). All these elements might contribute to seeing migrant neighbours as a negative amenity, and one that affects housing market dynamics.

\footnotetext{
6 The survey results also suggest that a significant share of the Italian population think: that migration should be stopped to reduce tension $(70 \%)$; that immigrants contribute less to public welfare $(68 \%)$; that immigrants take jobs away (66\%); and that immigration is bad or good for a country's economy (55\%). See Fig. 1 in appendix 1.

7 Cross-country analyses indicate that native workers tend to have a negative attitude towards those immigrants who are in direct competition with them on the national labor market (Kenneth and Slaughter 2001; Mayda 2006).

8 Bianchi et al. (2012) examine, empirically, the relationship between immigration and crime across Italian provinces during the period 1990-2003. The study states that immigration increases only the incidence of robberies, which represent a very small fraction of all criminal activities; the effect on the overall crime rate is not significantly different from zero.
} 
However, the complex interplay between the increased demand for housing due to the inflow of migrants and natives' preferences for sharing spaces with migrants and its effect on local housing values is hard to predict. It needs an empirical study.

In general, studies considering the impact of immigration on house prices and rents within metropolitan areas (cities, towns and neighbourhoods) are closely related to the sociological literature on ethnic segregation. The roots of the research on segregation lie in the literature developed by the Chicago School of Social Ecology which states that segregation in cities can be explained by the fact that people tend to segregate themselves along class, race and ethnic lines. ${ }^{9}$ Later studies introduced the time dimension of segregation and the concept of the 'tipping point' (Schelling 1971, 1978; Yinger 1985, 1995). This implies a critical concentration of foreign populations which is still acceptable to natives. Once the share of foreign nationals exceeds this threshold, natives begin to leave for other residential areas where the foreign concentration is lower. This idea developed by Schelling (1971) was applied in economic studies as well. Card et al. (2008), particularly, consider the influence that changes in the concentration of black residents have on the dynamics of racial composition in given neighbourhoods. Their results confirm the existence of a 'tipping point' around 5-20\% minority share and suggest that the tipping point varies across cities and depends on the racial attitudes of white Americans, income differences, crime rates and measures of past racial tension. Despite 'tipping' behaviour in white population residential decisions, both rental prices and house prices evolve smoothly through the tipping point (Card et al. 2008). Boustan (2010) estimates the extent of 'white flight' or the relocation of the white population from central cities to the suburban ring during the post-war period; the arrival of every black resident was, she suggested, associated with the departure of 2.7 whites. Moreover, in otherwise declining areas, the inflow of black migrants from the south led to an increase in vacancy rates and to a decline in house prices (Boustan 2010).

Saiz (2003) was the first author to look at the impact of international migration on housing market dynamics following the Mariel Boatlift episode: an inflow of Cuban migrants to Miami in 1980 resulted in a 9\% rise in Miami's renter population. The study reports that this exogenous migration shock led to a significant increase in average rents in the area. The impact was stronger for dwellings occupied by Hispanic residents, while higher quality accommodation was not affected. Unlike rents, house prices moved in the opposite direction most probably driven by native flight from the area. Saiz (2007) claims that the economic impact of migrants on the housing market is of a larger magnitude than in the labour market. Immigration pushes up rents and housing values in US destination cities; an immigration inflow leading to a $1 \%$ population increase in a city is associated with a $1 \%$ increase in average rents and housing values. At a more disaggregated (neighbourhood) level analysis there is a negative impact; growing immigration density is associated both with slower housing value appreciation and with native flight (Saiz and Wachter 2011; Mussa et al. 2017). Moreover, ethnicity and education dominate over foreignness

\footnotetext{
9 See, for example, Park and Burgess (1925), Park (1926, 1936, 1955), Sandoval (2000), Drake and Cayton (1945) and Duncan and Duncan (1957).
} 
per se in explaining any negative impact. Li (2014) looks at the impact of migrants' presence through the lenses of diversity and finds that neighbourhoods with more homogeneous minority populations are associated with higher prices in Vancouver, Canada. This and other findings support the notion that non-market social interactions influence preferences and behaviour.

In the European context, most of the literature on the migrant's impact on the housing market is focused on: (1) the patterns of ethnic segregation (Karsten et al. 2006; Andersson et al. 2018; Malmberg et al. 2018); (2) the institutional framework affecting its extent (Arbaci 2007, 2008; Arbaci and Malheiros 2010; Andersson et al. 2010; Skifter Andersen et al. 2016); and (3) policies combatting its adverse consequences (Musterd 2005; Paasche and Fangen 2011; Phillips 2010; Bolt et al. 2009). The generous welfare regime, social housing, regulated rental market, and dispersal policies attenuate the impact of migrants on house prices and rents. Yet, the few existing studies looking at the impact of the inflow of migrants on local housing market dynamics in Europe document some causal impact, the magnitude and direction of which, however, varies significantly across studies. Sá (2014) looks at the effect of immigration on house prices of 170 local authorities in England and Wales and finds that immigration has a negative effect on house prices due to the mobility response (outflow) of the native population: a $1 \%$ increase in immigrant population leading to a $1.7 \%$ reduction in house prices. The negative impact reported by Sá (2014) remained robust to the inclusion of the quality and location of the housing, as well as the skill levels or incomes of the migrants in later studies (Braakmann 2019; Zhu et al. 2018). All three studies suggest that the negative effect is driven by poorer areas attracting low-educated migrants. Ong (2017) looks for the potential 'tipping point' in the ethnic composition of neighbourhoods in Dutch cities. The study claims that native Dutch and Western minorities do not exhibit 'tipping' behaviour and claims that the large social housing sector, the centralised tax regime, and the strong regulatory role of the state in housing and urban planning are the main factors behind this. Still for the Netherlands, Daams et al. (2019) find that opening asylum seekers reception centres leads to, approximately, a 9.3\% fall in nearby house prices. However, this is the case only for single-family houses in less densely populated areas. Gonzalez and Ortega (2013) look at the impact of immigration on average house prices at the provincial level in Span over the period 2000-2010. The authors claim that immigration which led to an average $1.5 \%$ annual increase in the working-age population which led to annual increase in housing prices of about $2 \%$ and was responsible for one quarter of the increase in prices over the decade. d'Albis et al. (2019) analyse the impact of non-EU migrants on house prices at the regional level from 1990 to 2013. Their results suggest that immigration had no significant effect on prices and that higher house prices reduce immigration. The authors explain the absence of the effect by peculiarities of migration from non-EU migrants dominated by family-related migration and the importance of social housing. The estimated effect varies not only across but also within countries. So, in Switzerland an immigration inflow from a non-common language country equal to $1 \%$ of an area's population was found to be associated with an increase in prices for single-family homes of about $4.9 \%$. The inflow from 
a common language country has, meanwhile, no statistically significant impact (Fischer 2012). This last result indicates how the effect can vary significantly across different migrant groups and that the difference might be due to cultural proximity, education level, etc.

Antoniucci and Marella (2017) using on information on housing prices and socioeconomic factors concerning 112 Italian provincial capitals demonstrate that larger immigrant population coincides with steeper housing price gradients on a national scale. Accetturo et al. (2014) is closest to our study in terms of spatial unit considered. This work examines the impact of immigration on segregation patterns and house prices in urban areas. The results indicate that, though immigration lifts average house prices at the city level, it reduces price growth in the districts affected by the inflow with respect to city averages. The study also demonstrates that natives move from immigrant-populated districts towards other areas of the same city, which indicates that migrants are perceived as a negative local amenity by natives. This is in line with the evidence provided by Saiz and Wachter (2011) for housing dynamics across the USA. Overall, the studies focused on the Italian housing market demonstrate that migrants affect house price dynamics, though the direction and the magnitude of the estimated effect varies significantly due to the spatial unit of observation chosen: provinces in Kalantaryan (2013), provincial capitals in Antoniucci and Marella (2017) and city districts in Accetturo et al. (2014). In this respect, our study has the potential to provide further evidence by exploring the impact of migrants on smaller and uniform (in housing-market terms) spatial units.

\section{Methodology}

\subsection{Empirical Strategy}

The empirical specification employed to obtain regression coefficients describing the relationship between housing values and migrant settlement in Italian provincial capitals is the following:

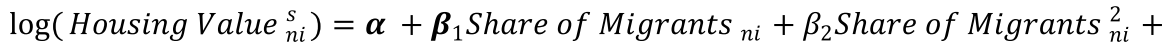

$$
\begin{aligned}
& \boldsymbol{\gamma} \text { Entropy Index }_{n i}+\boldsymbol{\delta} \text { Urban Zones }_{f}+\mu_{i}+\varepsilon_{n i}
\end{aligned}
$$

where the dependent variable, Housing Value, is the log transformation of minimum and maximum house prices and rents per square meter. The superscript $s$ stands for the State of Conservation of the residential unit which can be good or normal. On the right-hand side, the following set of control variables is included: Share of Migrants and its square term in OMI micro area $n$ in provincial capital $i$ (to capture potential non-linearity of relationship), Entropy index, Urban Zones which indicates whether the OMI micro area is situated in a central, semi-central, periphery, suburban area, a set of dummies $\left(\mu_{i}\right)$ which are supposed to capture municipality specific effects. 
Unfortunately, the cross-sectional nature of the dataset does not allow for controlling for single OMI area effects. ${ }^{10}$ Finally, $\varepsilon_{n i}$ is the idiosyncratic error. Entropy index is developed following Shannon's (1948) methodology based on the top ten origin groups specific to the OMI micro area. It is calculated with the following formula. ${ }^{11}$

$$
\text { Entropy Index }=-\sum_{o}\left(p_{o} * \log \left(p_{o}\right)\right)
$$

where $p_{o}$ is the share of migrants from origin $o$ in the OMI micro area.

The above presented basic specification is further enriched by including a set of variables for capturing the impact of the migrant population across neighbourhoods in terms of origin country. The first specification included variables measuring shares of migrants from high and low income countries, and the share of migrant from African countries. In the second specification there are the shares of migrants from the most important countries of origin. ${ }^{12}$

The coefficients obtained through the model presented in Eq. 1 might be biased and inconsistent due to endogeneity issues. Moreover, the direction of the bias is not easy to predict a priori. There are at least two reasons why migration flows and settlement may be endogenous to house prices and rents in the area. The first one is reverse causality. Migrants may be attracted by inexpensive housing and may avoid areas where house prices are growing faster than the municipality average. The second reason is related to omitted variables. ${ }^{13}$ For instance, if the factors responsible for the decline in the value of neighbourhoods are correlated with migration intensity, then their omission can lead to a downward bias in the coefficient of interest. Migrants may be attracted to neighbourhoods that are experiencing developments in public goods or amenities such as improvements in public transport or in health systems. Omitting these variables could lead to an overestimation in the association between the share of migrants and house prices. The second drawback is the possible displacement of natives by migrants. If natives move out from cities due to the arrival of migrants, it will prove difficult to detect the influence that migrants have on housing markets through changes in house prices and rents; the effect of migrant inflows will be offset by the outflow of natives. Given the low emigration rate with respect to the migration rate in Italy, one can say that an additional migrant increases the total population of a country by one person at the national level. However, the

\footnotetext{
${ }^{10}$ While information on the residential settlement of foreign populations with high geographic resolution is available for 2001 and 2011, the housing values started to be collected only in 2003, initially in a very fragmented manner. As a result, 2011 is the only point in time for which both housing values and population related information is available.

${ }_{11}$ The following statistical package was used https://cran.r-project.org/web/packages/diverse/diverse.pdf.

12 The share of migrants coming from the following countries of origin are included in the second specification: Romania, Albania, Morocco, China, Germany, Switzerland, Ukraine, Moldova, Philippines, India, Bangladesh, Peru, Ecuador, Northern Macedonia, Pakistan, France, Tunis, Senegal, Egypt, Poland, Sri Lanka, the UK, the USA and Belgium.

${ }^{13}$ Unfortunately, there is not much information available at the neighborhood disaggregation level; therefore, it is surer to omit some important neighborhood specific variables rather than in controlling for them. Moreover, some of the omitted time invariant variables, such as geographic position and industrial structure are important factors defining the residential choices of immigrants. The systematic correlation between the immigration flows and omitted time invariant municipality specific variables will lead to biased and inconsistent pooled OLS estimates.
} 
absence of displacement at the national level does not guarantee its absence at the local level; in this case, at the level of the Italian municipalities and neighbourhoods.

By addressing the above issues econometric theory proposes using an Instrumental variable (IV) approach, which implies using a variable(s) which is not (are not) included in the baseline model and which satisfies two conditions. It must be uncorrelated with the errors term $\varepsilon_{n i}$ and correlated with the potentially endogenous variable. In other words, an ideal candidate for an instrumental variable for migrant presence must not be correlated with all those factors that influence the evolution of local house prices. It must also be correlated with the current stock of migrants.

Migrants tend to cluster in proximity to their compatriots, which allows past settlement patterns to be used to build an instrumental variable for the current one. Both the economic and sociological literature offers rich evidence in support of this fact. ${ }^{14}$ Taking advantage of the properties of the historic settlement of migrants and following the methodology used in many related studies, we construct a predicted stock of migrants to instrument the actual one. It is based on the overall changes in the stock of migrants from one period to another and their initial distribution across neighbourhoods of Italian provincial capitals.

$$
\widetilde{M i} g_{n i, 2011}=\operatorname{Mig}_{n i, 2001}+\sum_{o=1}^{O} \theta_{o n i, 2001} \cdot \Delta M_{i g} g_{\text {Total }, 2011}
$$

where $\theta_{\text {oni,2001 }}$ represents the initial (historic) distribution of migrants across the neighbourhoods of Italian provincial capitals by single country of origin and is calculated based on the population census conducted in $2001 .{ }^{15} \Delta M i g_{\text {oTotal, } 2011}$, instead, is the estimated total inflow of new migrants to Italian provincial capitals by single country of origin since 2001. It is calculated as the difference in the number of migrants from a particular origin country in 2011 and 2001. The predicted number of migrants in a neighbourhood of the provincial capital $i$ in $2011 \widetilde{M i} g_{n i, 2011}$ is calculated as the product of these two elements added together across single countries of origin plus the number of migrants in 2001 (Fig. 2 in Appendix 1).

The above presented variable meets both conditions necessary for it to serve as an instrument for the current stock of migrants. Migration-related literature presents many non-economic factors determining the decision upon the destination for international migrants. The prior existence of enclaves of migrants from one country is an important magnet for future flow from the same territory. Indeed, it is reasonable to expect that the network effect plays a significant role in making a decision for the final destination; new migrants tend to settle in areas which are relatively densely populated by their compatriots in order to benefit from their support (Borjas 1995). The tendency of migrants to settle in close proximity to their compatriots can also be explained by the fact that established migrants share similar interests and possess useful information for those looking for a job or for housing. Migrants to Italy consider the search for decent housing to be the second in difficulty biggest obstacle that they face other than finding a job. The problem is amplified by the fact that there is not any system

\footnotetext{
${ }^{14}$ See, for example, Card (2001, 2007), Saiz (2007), Ottaviano and Peri (2007), Cortes (2008), Gonzalez and Ortega (2013), Saiz and Wachter (2011) and Borjas (1995).

${ }^{15}$ This is the earliest date for which the Data for Integration project provides information on foreign residents in Italy with high geographic resolution.
} 
of information, coordination or assistance to guide migrants in the new environment (Sunia 2009). As a result, migrants generally rely on their private contacts, networks of friends or colleagues, in searching out houses. ${ }^{16}$ These friends and colleagues are most likely to possess information about vacant residential units for the areas where they live, rather than for other areas. ${ }^{17}$ It is supposed that the instrument based on the past settlement pattern also meets the second validity condition. More specifically, it is assumed that the initial distribution of migrants is not correlated with the omitted variables, which might influence the future dynamics of the housing market. This assumption implies that based on the set of available information migrants cannot forecast the future of the housing market in any neighbourhood $n i$ better than natives do. House prices are the capitalized discounted value of the stream of future rents. If one believes that migrants are able to pick future "winner" locations based on the information available at present, then one has to explain why natives did not capitalize on the same set of available information (Saiz 2007). Second, changes in migrant flows at the national level are exogenous with respect to changes in municipality-specific amenities.

\section{Data}

To explore the relationship between the presence of migrants and housing values in Italian provincial capitals we use two sources of information. The first is a dataset developed by the EC's Knowledge Centre on Migration Demography (KCMD). It is based on the 2001 and 2011 Italian population censuses and provides information on residing population by single country of birth for the whole country with high geographic resolution $(100 \times 100 \mathrm{~m}$ cell $) .{ }^{18}$ The second source of information is the dataset on house prices and rents provided by the Observatory of Real Estate Markets (Osservatorio del Mercato Immobiliare-OMI) within the Italian fiscal authority (Agenzia delle Entrate). ${ }^{19}$ The Observatory provides estimates of house prices

\footnotetext{
16 According to Ponzo (2009) both pioneer and follower migrants use, almost exclusively, "informal channels" or personal contacts and only after obtaining a permit of stay or some other legal status do they turn to formal channels such as specialized magazines or real-estate agencies. However, formal channels do not work effectively if the target is renting, instead. An interested reader can find more details regarding precarious housing conditions of migrants in Italy in more recent studies, for instance, Fravega (2018), Petrillo (2018) and Mollick (2016).

17 Figure 3 in Appendix 1 demonstrate the strong relationship between the actual and the predicted stock of migrants in 2011. The results of the univariate regression confirm that the predicted flow is positively and statistically significantly correlated with the actual stock.

18 For more details on the methodology used to develop the high resolution data see Alessandrini et al. (2017).

19 The main alternative data sources for house prices in Italy are: Scenari Immobiliari; Nomisma; and Consulente immobiliare: Scenari Immobiliari is a specialized research institute, which provides information on the dynamics of housing prices with highly-detailed data for 150 cities. The data is superior with respect to the $O M I$ if the main subject of interest is the time dimension (available from 1965) and vice versa if the subjects of interest are qualitative characteristics and geographic coverage. Nomisma data collection contains detailed information on the average prices reported by a sample of real estate agencies. However, it has a narrow geographic coverage: only thirteen large and thirteen middle-sized provin-
} 
and rents (maximum and minimum) in Italy disaggregated to the OMI micro area level. ${ }^{20}$ To give a better understanding of the data employed in this study, it is worth presenting some details related to the methodology used in obtaining housing market estimates. Each OMI micro area can refer to a small municipality or a district/ street of a bigger one. The division is made taking into account factors which are responsible or explanatory for positional differences in the values of different housing units. The resulting OMI micro areas are homogeneous territorial units which express similar market levels according to common characteristics. They reflect homogeneous segments of the local property market with substantial uniformity in respect to environmental and socioeconomic conditions. One of the requirement for defining an OMI micro area is that the ratio between maximum and minimum values within it should not exceed 1.5. The information on housing values is available for three types of residential units: civilian, economic and prestigious houses/villas. In this study values for civilian and economic residential units are used. While the information on prices for civilian residential units has wider geographic coverage compared to economic ones (1903 vs 1608 for prices and 1864 vs 1572 for rents), the latter has higher relevance as low-income migrants gravitate to cheaper housing units. For each OMI micro area we have information on the state of conservation (good and normal) and position with respect to the city centre (central, semi-central, periphery, suburban). Table 1 in Appendix 1 provides an example of the set of information available for an OMI micro area in the municipality of Turin.

The dataset, from merging these two sources, contains information on residing population by single country of birth for each OMI micro area in Italian provincial capitals. The average minimum and maximum house prices per square meter are between roughly 1900 and 2500 Euros. The average minimum and maximum housing rents per square meter are around 6 and 8 Euros. All four measures of housing values vary dramatically.

Migrants are defined based on country of birth criterion, though the original dataset contains information on country of citizenship, too. On average the share of migrants in OMI micro areas included in our sample is $9 \%$. However, it varies significantly across and within provincial capitals. ${ }^{21}$ The average share of migrants is lowest in Barletta, Carbonia and Potenza (2\%) and highest in Trieste, Brescia, Iglesias, Piacenza and Udine (more than 17\%). Neighbourhoods with foreign-born residents constituting more than half of the population are to be found in Rome (86\%),

\footnotetext{
Footnote 19 (continued)

cial capitals. Another data source is Il Consulente immobiliare, which is a specialized review published by Il Sole 24 Ore media group. It covers all provincial capitals and more than 1000 municipalities. The main shortcoming of this data is, first, the rotation of the sample, which creates continuity issues, second, and the absence of an adequate data collection methodology, especially when the municipality is not a provincial capital.

${ }^{20}$ OMI works together with FIAP (Italian Federation of Real Estate Agents), FIMAA (Italian Federation of Intermediate Renting Agents), CNI (National Conceal of Engineers), AICI (Italian Association of Leasing), Nomisma, Fondazione Instituto Guliermo Tagliacarne, Technoborsa, Cresma, Istat, Econpubblica, Universita Bocconi and the Agenzia delle Entrate. The initial raw information comes from the direct survey of actual prices quoted by market operators and the administrative archives. In the next step, it combines with evaluations of local real estate experts to correct imperfections in the raw information.

21 See Table 2 in appendix 1.
} 
Iglesias $(75 \%)$ and Ragusa $(66 \%){ }^{22}$ There is a significant variation in the composition of migrant populations observed across OMI micro areas. The Entropy index calculated for OMI micro-area-specific top ten origin countries goes from zero to 1.30, with an average of 0.39 . Table 2 in Appendix 1 provides detailed statistics on the share of migrants from country groups (high- and low-income and African countries) and single main countries of origin.

\section{Results}

Tables 4, 5, 6, 7, 8, 9, 10 and 11 in appendix 1 summarise the results of regressions based on the empiric specification presented in the previous section and they follow the same structure. In all tables Column (1)-(4) present the results of regressions where the dependent variable is house prices. Column (5) and (8) report the results of regressions where the dependent variable is minimum and maximum housing rents. There are two sets of results that refer to two specifications. The first specification, in addition to variables presented in Eq. 1, includes the shares of migrants coming from high and low-income, as well as from African countries (Tables 4, 5, 6, 7 in appendix 1). The second specification instead includes the shares of migrants coming from 'top' origin countries (Tables 8, 9, 10, 11 in appendix 1). Moreover, for each specification, we report results for civilian and economic residential units in a normal and in a good state of conservation.

The set of results reported in Tables 4 and 6 in appendix 1 capture the relationship between the settlement pattern of migrants and house prices and rents for respectively civilian and economic residential units in a normal state of conservation, while additionally controlling for the composition of the migrant population by the income level of the country of origin. The OLS results presented in Columns (1), (2), (5), and (6) indicate that both house prices and rents are statistically significantly correlated with the presence of migrants. The positive coefficients for share of migrants and negative ones at its square term indicate that the relationship between the presence of migrants and housing values is positive, but at a declining rate. While the coefficients for the share of migrants from high income and low-income countries (within the migrant population) are not statistically significant those for share of migrants from African countries (within the migrant population) are negative and statistically significant for house prices. IV estimation results presented in Columns (3), (4), (7), and (8) confirm the OLS results. The coefficients for the share of migrants and its squared term preserve both the sign and statistical significance. Share of migrants from high- and low-income countries remain statistically not significant. Instead, the negative coefficient for the share of migrants from African countries loses its significance for both house prices and rents. ${ }^{23}$

\footnotetext{
22 See Table 3 in appendix 1.

23 In all specifications the first stage coefficients for the instrumental variable and the F statistics point to the validity of the instruments. Unfortunately having only one instrument for the potentially endogenous explanatory variable leads to exact identification and does not allow for perform an over identification test.
} 
Tables 5 and 7 in appendix 1 report results for the same specification for civilian and for economic residential housing units in a good state of conservation. Both OLS and IV estimation results for the share of migrants are in line with those reported in Tables 4 and 6 in appendix 1. For housing units in a good state of conservation, we detect a negative association between house prices and the share of migrants from African countries. The IV estimation coefficients remain negative and statistically significant, though slightly smaller in magnitude. Similarly, the IV estimates confirm the negative association between the share of low-income countries with rental prices for housing units in a good state of conservation. Two variablesthe share of migrants from African and low-income countries-seem to mark out the low-income group and capture the same effect. It is important to note that the estimates obtained for housing units in a good state of conservation are based on only 487 observations for prices and 398 for rents, which is less than one-quarter of the sample available for housing units in a good state of conservation. The number of observations available for economic residential units in a good state of conservation is even smaller; respectively, 215 and 175 for prices and rents. Hence, these results should be interpreted with caution. ${ }^{24}$

The second set of results demonstrates the impact of migrant composition (net of the overall effect of foreign presence) by further disaggregating the migrant population and by considering the shares of the top twenty-three origin countries in terms of numbers of migrants. It is necessary to mention that variables measuring single country-specific migrant shares are likely to underrepresent the true presence of migrants from a particular origin state. This is due to the specific processing applied to census data to obtain population information at high spatial resolution. In particular, in addition to the confidentiality thresholds applied by the Italian National Statistical Institute, records (combinations of census area and origin) with a population count of fewer than five persons were removed (Alessandrini et al. 2017). The resulting measurement error, which is naturally larger for smaller origin communities, leads to Classical Errors-in-Variables (CEV) and attenuation bias. Hence the reported coefficients indicate the direction rather than the true magnitude of association and should be interpreted with caution. Overall the objective of the second specification is to test the robustness of coefficients obtained for migrant share and entropy index. To be consistent with the logic above, first, the results obtained for civilian and economic housing units in a normal state of conservation are discussed. As in the previous specification results reported in Tables 8 and 10 in appendix 1 point to a non-linear relationship between housing values and migrant presence. The single country of origin-specific coefficients vary both by type of residential units (civilian and economic). The OLS estimation results indicate that the presence of migrants from Romania, Morocco, China, Germany, Ecuador, Pakistan, Senegal, Egypt, and Belgium are negatively associated with house prices and to a lesser extent with rents for civilian residential units. For economic residential units

\footnotetext{
${ }^{24}$ Unfortunately, the number of observations available for poor housing units is very small. This does not allow us either to report the results or to draw conclusions at the national level, despite the fact that those dwellings might be demanded by migrants due to their relatively low incomes.
} 
the presence of Germans is negatively associated with house prices but not with rent, while the presence of those of Belgians is not significant either for prices or rents. Instead, migrants from Ukraine, the Philippines, and the USA are associated with higher house prices and rents for civilian residential units. The same holds true for economic residential units. The exception is the share of migrants from the Philippines for which the coefficients are positive but statistically not significant. The IV results confirm the non-linear relationship between housing values and the presence of migrants. While the results for single country of origin shares are confirmed for cases where OLS detected a negative relationship; in the case of positive coefficients, only the share of migrants from Ukraine is confirmed by IV estimation for prices and rents (both types of residential units). The IV results also suggest a positive association between the presence of foreign-born individuals of US origin but only for prices and rents for economic residential units.

The results obtained for civilian and economic residential units in a good state of conservation provide an additional set of information (Tables 9, 11 in appendix 1). They confirm the results obtained for share of migration both in OLS and IV. But they also reveal a statistically significant positive relationship between Swiss/ Ukrainian migrants and house prices and rents, and a negative one for migrants from Ecuador. This might indicate that, after controlling for the share of migrants (and its squared term), the composition of migrants by origin does not contribute much to explaining prices and rents for housing units in a good state of conservation. However, as in the first specification, this set of results relies on a smaller sample of observations and hence should be interpreted with caution.

Figure 4 in Appendix 1 illustrates the non-linearity between housing values and the presence of a foreign-born population based on the coefficients of migrant share and its square term reposted in Tables 4 and 6 in appendix 1. Interestingly, for civilian residential units, all four pairs of OLS coefficients suggest the same tipping point: once the concentration of migrants reaches $55 \%$ the relationship turns from a positive to a negative one. The IV estimation confirms the non-linear pattern, but suggests an earlier tipping point, at around $44 \%$. For economic residential units, the estimated tipping points vary from $48 \%$ for minimum rents to $59 \%$ for maximum prices. $^{25}$ As with civilian residential units the tipping point suggested by IV estimation for economic units is lower: about $40 \%$ for minimum rents and $43 \%$ for maximum house prices.

The regression results of all specifications for both types of residential units point to a negative relationship between the diversity of the population in terms of origin and house prices and rents. The negative coefficient for the entropy index indicates that more diverse neighbourhoods are those characterised by relatively low house prices and rents. In all reported cases the IV coefficients preserve the negative sign and are of higher magnitude. This proves to be even more so for housing units in a good state of conservation.

\footnotetext{
25 The tipping point estimated for minimum rents is $42 \%$. However, the coefficient for the share of migrants is not statistically significant at the $10 \%$ level.
} 


\subsection{Robustness Checks}

We repeat the whole set of above-presented estimations by restricting the sample observations to those OMI areas for which information on prices and rents of both civilian and economic residential units are available. This allows for a comparison of the two sets of coefficients, estimated for the housing values of civilian and economic residential units. Table 12 in appendix 1 summarises the results of the first specification by presenting the coefficients of main interest (share of migrants, its squared term, and entropy index), as well as the number of observations, clusters (provincial capitals) and R2. ${ }^{26}$ The reported results confirm those obtained for the whole sample; the non-linear relationship for the share of migrants and the negative association between the diversity of population for civilian and economic residential units. Also for residential units in a good state of conservation, despite an extremely limited number of observations covering only a few municipalities, the results are in line with those obtained for the whole sample and for the restricted sample of residential units in a normal state of conservation. Interestingly for the restricted sample of residential units in a normal state of conservation the estimated tipping points converge; IV estimation stands at around 40\% for house prices and rents for civilian and economic units. For the entropy index, the following pattern is observed: (1) the magnitude of coefficients estimated for maximum prices and rents are always larger than those of minimum ones; (2) the magnitude of coefficients estimated for civilian residential units are always larger than those for economic ones; and (3) the magnitude of coefficients estimated for residential units in good state of conservation are always larger than those for the normal state of conservation.

Figures 5, 6 and 7 in appendix 1 are a set of maps which compare information on a foreign presence and average house prices in two Italian provincial capitals: Bologna and Turin. These cities had an approximately $11 \%$ foreign-born population in 2011. The maps reveal that in both cities the presence of migrants is more evident in neighbourhoods with relatively cheap house prices (Fig. 5 in Appendix 1). This pattern is even more pronounced for migrants of African origin (Fig. 6 in Appendix 1). Moreover, neighbourhoods with a more diverse population-characterised by a higher entropy index - are those with lower house prices (Fig. 7 in appendix 1). The higher the entropy index the darker the shaded area. These maps, also, confirm the estimation results; more diverse neighbourhoods are characterised by relatively lower average house prices.

\section{Conclusions}

There is increasing discussion in the social sciences about the consequences of intense immigration to European countries. Research in this field is mainly concentrated on the impact migration has on labour market outcomes for pre-migration populations and for migrants themselves. This study looks for an alternative channel through which immigration affects the well-being of natives by empirically

${ }^{26}$ The full set of these extra results are available upon request. 
examining the relationship between the presence of migrants and housing valuesprices and rents-in Italy. The purpose of this exercise is twofold. First, it aims at demonstrating the potential of the high resolution dataset on migrants' presence developed within the D4I project, in combination with information on real estate values. Second, benefiting from information on housing values at the neighbourhood level in Italy, the study explores the relationship between house prices and rents and the residential settlement of migrants in Italian provincial capitals.

The regression analysis suggests that more diverse neighbourhoods are also those with relatively lower housing values. Moreover, the relationship between housing values and the concentration of migrants is non-linear. It is positive but at a declining rate. The positive association is observed for neighbourhoods with a concentration of migrants below a threshold of $44-45 \%$ of the total population, after which the relationship turns to a negative one. While the positive association might be attributed to the extra demand created by the inflow of migrants, the negative association might also be the result of the reaction of natives to migrants in the neighbourhood ('native flight'). If natives consider the presence of migrants to be a negative local amenity the demand for housing in neighbourhoods where migrants are present will decrease. This will result in a decline in house values and rents allowing more migrants to settle in the neighbourhood. The concentration of migrants thus grows. Interestingly, an earlier study documents the non-linear relationship between the presence of migrants and labour market opportunities for native born workers in Italy. In particular, once the share of foreign workers exceeds $10-14 \%$ of employed (at sector specific regional level), natives and migrants will stop complementing each other and will begin to compete in the labour market (Gavosto et al. 1999).

The above presented discussion suggests some ambiguity in terms of the relationship between the presence of migrants and housing values. In addition to being non-linear the origin of migrants proves crucial. Some groups of migrants are associated with relatively higher prices while others are associated with lower ones. The regression results also demonstrate that the sign and significance of the association vary significantly depending on the origin of migrants. Migrants from Romania, Morocco, China, Ecuador, Pakistan, Senegal, Egypt, and Belgium are negatively associated with housing values. Instead, Swiss and Ukrainian migrants are associated with higher housing values. The positive association of the Swiss might be explained by good financial resources; the positive association of Ukrainians is likely to be due to the fact that migrants from this country are mostly employed as in-house caregivers and hence live in relatively wealthy households in neighbourhoods with higher housing values.

The analysis does not fully explore the causal relationship between housing value dynamics and the presence of migrants. This is due to the absence of panel data with high geographic resolution on housing values and the settlement of migrants. Yet, overall, the instrumental variable estimation confirms the OLS results. One of the interesting differences detected between the OLS and IV results is the discrepancy in the threshold after which the positive relationship between the share of migrants and housing values turns to a negative one. IV estimates suggest a lower threshold between 40 and $45 \%$ compared to the one reported by the OLS. 
Overall, the study shows a complex relationship between any foreign presence and the housing market. It also suggests ongoing ethnic residential segregation in Italian cities. Understanding the drivers of these dynamics will require further research and the attention of policymakers.

\section{Compliance with Ethical Standards}

Conflict of interest On behalf of all authors, the corresponding author states that there is no conflict of interest.

Open Access This article is licensed under a Creative Commons Attribution 4.0 International License, which permits use, sharing, adaptation, distribution and reproduction in any medium or format, as long as you give appropriate credit to the original author(s) and the source, provide a link to the Creative Commons licence, and indicate if changes were made. The images or other third party material in this article are included in the article's Creative Commons licence, unless indicated otherwise in a credit line to the material. If material is not included in the article's Creative Commons licence and your intended use is not permitted by statutory regulation or exceeds the permitted use, you will need to obtain permission directly from the copyright holder. To view a copy of this licence, visit http://creativecommons.org/licen ses/by/4.0/.

\section{Appendix 1}

Table 1 The set of information available for the OMI micro areas

\begin{tabular}{|c|c|c|c|c|c|c|c|}
\hline \multirow[t]{2}{*}{ Type of dwelling } & \multirow[t]{2}{*}{ State of conservation } & \multicolumn{2}{|c|}{$\begin{array}{l}\text { Price (€/sq. } \\
\text { m) }\end{array}$} & \multirow[t]{2}{*}{ Surface $(\mathrm{L} / \mathrm{N})$} & \multicolumn{2}{|c|}{$\begin{array}{l}\text { Monthly } \\
\text { rent (€/sq. } \\
\mathrm{m})\end{array}$} & \multirow[t]{2}{*}{ Surface $(\mathrm{L} / \mathrm{N})$} \\
\hline & & Min & Max & & Min & Max & \\
\hline Civil housing & NORMAL & 1600 & 2100 & $\mathrm{~L}$ & 6.0 & 8.8 & $\mathrm{~L}$ \\
\hline Civil housing & GOOD & 1900 & 2750 & $\mathrm{~L}$ & 7.1 & 10.0 & $\mathrm{~L}$ \\
\hline Economic housing & NORMAL & 1200 & 1800 & $\mathrm{~L}$ & 5.1 & 7.5 & $\mathrm{~L}$ \\
\hline
\end{tabular}

The reported estimates refer to OMI micro area "Madonna di Campagna", which is located on the outskirts of the municipality of Turin, 2011. L and $\mathrm{N}$ stand for the total and useful surfaces 
Table 2 Descriptive statistics

\begin{tabular}{|c|c|c|c|c|c|}
\hline Variable & Obs. & Mean & SD & Min & Max \\
\hline Prices per sq. m (Max) & 2568 & 2525 & 1357 & 290.0 & 14,000 \\
\hline Prices per sq. m (Min) & 2568 & 1878 & 9988 & 220.0 & 10,000 \\
\hline Rent per sq. m (Max) & 2435 & 8.12 & 5.19 & 1.0 & 50.00 \\
\hline Rent per sq. m (Min) & 2435 & 5.94 & 3.77 & 0.9 & 35.00 \\
\hline Entropy Index & 2016 & 0.39 & 0.21 & 0.00 & 1.30 \\
\hline Share of migrants & 2016 & 0.09 & 0.06 & 0.00 & 0.86 \\
\hline Share of mig. from high income countries & 2016 & 0.06 & 0.07 & 0.00 & 0.60 \\
\hline Share of mig. from low income countries & 2016 & 0.01 & 0.02 & 0.00 & 0.47 \\
\hline Share of mig. from African countries & 2016 & 0.08 & 0.09 & 0.00 & 1.00 \\
\hline Share of mig. from Romania & 2016 & 0.11 & 0.11 & 0.00 & 0.68 \\
\hline Share of mig. from Albania & 2016 & 0.05 & 0.07 & 0.00 & 0.54 \\
\hline Share of mig. from Morocco & 2016 & 0.04 & 0.06 & 0.00 & 0.62 \\
\hline Share of mig. from China & 2016 & 0.03 & 0.06 & 0.00 & 0.72 \\
\hline Share of mig. from Germany & 2016 & 0.01 & 0.03 & 0.00 & 0.51 \\
\hline Share of mig. from Switzerland & 2016 & 0.01 & 0.04 & 0.00 & 0.42 \\
\hline Share of mig. from Ukraine & 2016 & 0.03 & 0.05 & 0.00 & 0.58 \\
\hline Share of mig. from Moldova & 2016 & 0.01 & 0.03 & 0.00 & 0.21 \\
\hline Share of mig. from the Philippines & 2016 & 0.03 & 0.05 & 0.00 & 0.42 \\
\hline Share of mig. from India & 2016 & 0.01 & 0.03 & 0.00 & 0.50 \\
\hline Share of mig. from Bangladesh & 2016 & 0.01 & 0.05 & 0.00 & 0.67 \\
\hline Share of mig. from Peru & 2016 & 0.01 & 0.03 & 0.00 & 0.21 \\
\hline Share of mig. from Ecuador & 2016 & 0.01 & 0.04 & 0.00 & 0.54 \\
\hline Share of mig. from N. Macedonia & 2016 & 0.01 & 0.03 & 0.00 & 0.71 \\
\hline Share of mig. from Pakistan & 2016 & 0.00 & 0.02 & 0.00 & 0.43 \\
\hline Share of mig. from France & 2016 & 0.01 & 0.02 & 0.00 & 0.54 \\
\hline Share of mig. from Tunis & 2016 & 0.01 & 0.02 & 0.00 & 0.46 \\
\hline Share of mig. from Senegal & 2016 & 0.01 & 0.03 & 0.00 & 0.56 \\
\hline Share of mig. from Egypt & 2016 & 0.01 & 0.02 & 0.00 & 0.19 \\
\hline Share of mig. from Poland & 2016 & 0.01 & 0.02 & 0.00 & 0.16 \\
\hline Share of mig. from Sri Lanka & 2016 & 0.02 & 0.05 & 0.00 & 0.55 \\
\hline Share of mig. from the UK & 2016 & 0.00 & 0.01 & 0.00 & 0.24 \\
\hline Share of mig. from the USA & 2016 & 0.00 & 0.01 & 0.00 & 0.21 \\
\hline Share of mig. from Belgium & 2016 & 0.00 & 0.01 & 0.00 & 0.27 \\
\hline
\end{tabular}

The information refers to 2011. House prices and rents are reported for civilian residential units only. The geographic unit is OMI micro area 
Table 3 Share of migrants and Entropy Index by provincial capitals

\begin{tabular}{|c|c|c|c|c|c|c|c|c|c|}
\hline \multirow[t]{2}{*}{ Municipality } & \multirow[t]{2}{*}{ OMI } & \multicolumn{4}{|c|}{ Share of foreign-born } & \multicolumn{4}{|c|}{ Entropy Index } \\
\hline & & Mean & S.D. & Min & Max & Mean & S.D. & Min & $\operatorname{Max}$ \\
\hline Agrigento & 15 & 0.06 & 0.04 & 0.02 & 0.16 & 0.27 & 0.15 & 0.12 & 0.60 \\
\hline Alessandria & 13 & 0.07 & 0.04 & 0.02 & 0.16 & 0.33 & 0.18 & 0.11 & 0.69 \\
\hline Ancona & 17 & 0.12 & 0.08 & 0.05 & 0.36 & 0.51 & 0.27 & 0.22 & 1.28 \\
\hline Andria & 2 & 0.02 & 0.01 & 0.01 & 0.02 & 0.11 & 0.04 & 0.08 & 0.14 \\
\hline Aosta & 18 & 0.09 & 0.03 & 0.03 & 0.16 & 0.41 & 0.14 & 0.18 & 0.71 \\
\hline Arezzo & 35 & 0.10 & 0.04 & 0.06 & 0.20 & 0.47 & 0.17 & 0.28 & 0.86 \\
\hline Ascoli Piceno & 16 & 0.07 & 0.02 & 0.04 & 0.12 & 0.32 & 0.09 & 0.20 & 0.55 \\
\hline Asti & 14 & 0.11 & 0.05 & 0.02 & 0.18 & 0.49 & 0.20 & 0.12 & 0.76 \\
\hline Avellino & 26 & 0.04 & 0.01 & 0.02 & 0.06 & 0.19 & 0.04 & 0.11 & 0.27 \\
\hline Bari & 22 & 0.03 & 0.01 & 0.01 & 0.06 & 0.17 & 0.08 & 0.06 & 0.30 \\
\hline Barletta & 3 & 0.03 & 0.01 & 0.01 & 0.04 & 0.15 & 0.07 & 0.08 & 0.21 \\
\hline Belluno & 11 & 0.10 & 0.04 & 0.06 & 0.18 & 0.45 & 0.13 & 0.29 & 0.71 \\
\hline Benevento & 5 & 0.04 & 0.01 & 0.03 & 0.06 & 0.20 & 0.06 & 0.15 & 0.29 \\
\hline Bergamo & 23 & 0.15 & 0.08 & 0.06 & 0.41 & 0.63 & 0.26 & 0.27 & 1.30 \\
\hline Biella & 7 & 0.11 & 0.09 & 0.04 & 0.31 & 0.41 & 0.13 & 0.20 & 0.62 \\
\hline Bologna & 36 & 0.12 & 0.03 & 0.09 & 0.20 & 0.54 & 0.11 & 0.38 & 0.86 \\
\hline Brescia & 23 & 0.17 & 0.07 & 0.07 & 0.32 & 0.69 & 0.25 & 0.35 & 1.10 \\
\hline Brindisi & 8 & 0.04 & 0.02 & 0.02 & 0.06 & 0.19 & 0.08 & 0.10 & 0.30 \\
\hline Cagliari & 11 & 0.05 & 0.03 & 0.02 & 0.11 & 0.25 & 0.14 & 0.09 & 0.51 \\
\hline Caltanissetta & 15 & 0.04 & 0.03 & 0.02 & 0.12 & 0.21 & 0.12 & 0.09 & 0.49 \\
\hline Campobasso & 18 & 0.04 & 0.02 & 0.02 & 0.08 & 0.22 & 0.07 & 0.08 & 0.38 \\
\hline Carbonia & 4 & 0.02 & 0.00 & 0.02 & 0.02 & 0.12 & 0.01 & 0.10 & 0.13 \\
\hline Caserta & 19 & 0.05 & 0.02 & 0.03 & 0.10 & 0.25 & 0.08 & 0.17 & 0.48 \\
\hline Catania & 27 & 0.05 & 0.03 & 0.01 & 0.14 & 0.23 & 0.14 & 0.07 & 0.60 \\
\hline Catanzaro & 28 & 0.03 & 0.02 & 0.00 & 0.08 & 0.17 & 0.08 & 0.00 & 0.36 \\
\hline Chieti & 20 & 0.06 & 0.02 & 0.02 & 0.13 & 0.26 & 0.08 & 0.11 & 0.48 \\
\hline Como & 12 & 0.14 & 0.04 & 0.04 & 0.22 & 0.58 & 0.15 & 0.22 & 0.88 \\
\hline Cosenza & 9 & 0.06 & 0.02 & 0.03 & 0.09 & 0.29 & 0.12 & 0.14 & 0.43 \\
\hline Cremona & 4 & 0.11 & 0.02 & 0.08 & 0.13 & 0.52 & 0.06 & 0.43 & 0.56 \\
\hline Crotone & 10 & 0.04 & 0.01 & 0.02 & 0.06 & 0.18 & 0.06 & 0.08 & 0.27 \\
\hline Cuneo & 30 & 0.10 & 0.04 & 0.04 & 0.18 & 0.45 & 0.16 & 0.16 & 0.73 \\
\hline Fermo & 19 & 0.09 & 0.05 & 0.04 & 0.26 & 0.40 & 0.18 & 0.19 & 1.00 \\
\hline Ferrara & 14 & 0.08 & 0.03 & 0.03 & 0.12 & 0.36 & 0.14 & 0.14 & 0.59 \\
\hline Firenze & 30 & 0.13 & 0.04 & 0.08 & 0.27 & 0.55 & 0.13 & 0.39 & 0.92 \\
\hline Foggia & 9 & 0.03 & 0.02 & 0.01 & 0.06 & 0.15 & 0.08 & 0.06 & 0.28 \\
\hline Frosinone & 9 & 0.08 & 0.02 & 0.04 & 0.12 & 0.37 & 0.08 & 0.22 & 0.52 \\
\hline Genova & 70 & 0.09 & 0.06 & 0.02 & 0.28 & 0.39 & 0.23 & 0.08 & 1.03 \\
\hline Gorizia & 5 & 0.16 & 0.05 & 0.10 & 0.22 & 0.70 & 0.17 & 0.46 & 0.90 \\
\hline Grosseto & 28 & 0.07 & 0.03 & 0.01 & 0.15 & 0.32 & 0.13 & 0.06 & 0.61 \\
\hline Iglesias & 5 & 0.17 & 0.32 & 0.01 & 0.75 & 0.21 & 0.20 & 0.08 & 0.56 \\
\hline Imperia & 21 & 0.12 & 0.04 & 0.07 & 0.19 & 0.54 & 0.14 & 0.32 & 0.81 \\
\hline
\end{tabular}


Table 3 (continued)

\begin{tabular}{|c|c|c|c|c|c|c|c|c|c|}
\hline \multirow[t]{2}{*}{ Municipality } & \multirow[t]{2}{*}{ OMI } & \multicolumn{4}{|c|}{ Share of foreign-born } & \multicolumn{4}{|c|}{ Entropy Index } \\
\hline & & Mean & S.D. & Min & $\operatorname{Max}$ & Mean & S.D. & Min & Max \\
\hline Isernia & 6 & 0.07 & 0.03 & 0.05 & 0.13 & 0.34 & 0.11 & 0.27 & 0.56 \\
\hline La Lspezia & 13 & 0.09 & 0.04 & 0.04 & 0.15 & 0.41 & 0.16 & 0.18 & 0.69 \\
\hline Latina & 12 & 0.07 & 0.02 & 0.04 & 0.12 & 0.33 & 0.10 & 0.19 & 0.54 \\
\hline Lecce & 23 & 0.07 & 0.06 & 0.03 & 0.31 & 0.31 & 0.16 & 0.14 & 0.82 \\
\hline Lecco & 19 & 0.09 & 0.05 & 0.04 & 0.29 & 0.43 & 0.19 & 0.21 & 1.04 \\
\hline Livorno & 19 & 0.07 & 0.03 & 0.03 & 0.14 & 0.30 & 0.16 & 0.00 & 0.66 \\
\hline Lodi & 11 & 0.11 & 0.03 & 0.07 & 0.17 & 0.48 & 0.13 & 0.32 & 0.75 \\
\hline Lucca & 9 & 0.10 & 0.02 & 0.06 & 0.13 & 0.44 & 0.08 & 0.29 & 0.54 \\
\hline Macerata & 14 & 0.12 & 0.06 & 0.04 & 0.22 & 0.52 & 0.18 & 0.20 & 0.82 \\
\hline Mantova & 10 & 0.13 & 0.04 & 0.10 & 0.21 & 0.61 & 0.16 & 0.44 & 0.90 \\
\hline Massa & 10 & 0.07 & 0.02 & 0.04 & 0.10 & 0.33 & 0.06 & 0.24 & 0.45 \\
\hline Matera & 7 & 0.05 & 0.02 & 0.03 & 0.08 & 0.24 & 0.09 & 0.15 & 0.38 \\
\hline Messina & 29 & 0.05 & 0.03 & 0.02 & 0.12 & 0.25 & 0.12 & 0.09 & 0.50 \\
\hline Milano & 55 & 0.14 & 0.04 & 0.08 & 0.24 & 0.62 & 0.16 & 0.39 & 0.99 \\
\hline Modena & 24 & 0.13 & 0.06 & 0.05 & 0.25 & 0.56 & 0.21 & 0.22 & 0.93 \\
\hline Monza & 12 & 0.10 & 0.02 & 0.08 & 0.14 & 0.47 & 0.08 & 0.35 & 0.63 \\
\hline Napoli & 66 & 0.04 & 0.03 & 0.01 & 0.12 & 0.19 & 0.12 & 0.05 & 0.53 \\
\hline Novara & 19 & 0.14 & 0.08 & 0.05 & 0.40 & 0.58 & 0.26 & 0.23 & 1.25 \\
\hline Nuoro & 17 & 0.03 & 0.01 & 0.02 & 0.05 & 0.16 & 0.04 & 0.10 & 0.24 \\
\hline Olbia & 8 & 0.07 & 0.04 & 0.01 & 0.13 & 0.28 & 0.15 & 0.07 & 0.50 \\
\hline Oristano & 4 & 0.03 & 0.01 & 0.02 & 0.05 & 0.18 & 0.05 & 0.14 & 0.25 \\
\hline Padova & 13 & 0.13 & 0.04 & 0.09 & 0.22 & 0.60 & 0.16 & 0.42 & 0.90 \\
\hline Palermo & 50 & 0.06 & 0.06 & 0.01 & 0.28 & 0.28 & 0.23 & 0.06 & 0.99 \\
\hline Parma & 12 & 0.11 & 0.04 & 0.05 & 0.19 & 0.50 & 0.15 & 0.21 & 0.77 \\
\hline Pavia & 15 & 0.10 & 0.02 & 0.07 & 0.13 & 0.43 & 0.08 & 0.33 & 0.58 \\
\hline Perugia & 13 & 0.12 & 0.03 & 0.08 & 0.17 & 0.52 & 0.11 & 0.39 & 0.75 \\
\hline Pesaro & 14 & 0.10 & 0.03 & 0.05 & 0.14 & 0.46 & 0.10 & 0.27 & 0.62 \\
\hline Pescara & 18 & 0.07 & 0.01 & 0.05 & 0.10 & 0.31 & 0.05 & 0.26 & 0.47 \\
\hline Piacenza & 7 & 0.17 & 0.06 & 0.11 & 0.29 & 0.73 & 0.20 & 0.51 & 1.11 \\
\hline Pisa & 13 & 0.11 & 0.04 & 0.05 & 0.19 & 0.46 & 0.12 & 0.27 & 0.66 \\
\hline Pistoia & 11 & 0.10 & 0.03 & 0.05 & 0.17 & 0.44 & 0.12 & 0.26 & 0.68 \\
\hline Pordenone & 7 & 0.16 & 0.05 & 0.11 & 0.25 & 0.67 & 0.18 & 0.47 & 0.98 \\
\hline Potenza & 6 & 0.02 & 0.01 & 0.01 & 0.04 & 0.13 & 0.04 & 0.07 & 0.19 \\
\hline Prato & 12 & 0.12 & 0.07 & 0.05 & 0.26 & 0.54 & 0.25 & 0.23 & 0.96 \\
\hline Ragusa & 14 & 0.07 & 0.10 & 0.02 & 0.41 & 0.29 & 0.25 & 0.12 & 1.10 \\
\hline Ravenna & 20 & 0.12 & 0.07 & 0.05 & 0.33 & 0.49 & 0.22 & 0.22 & 1.23 \\
\hline Reggio Calabria & 27 & 0.05 & 0.01 & 0.02 & 0.08 & 0.25 & 0.07 & 0.12 & 0.41 \\
\hline Reggio Emilia & 13 & 0.15 & 0.08 & 0.06 & 0.29 & 0.63 & 0.29 & 0.27 & 1.16 \\
\hline Rieti & 8 & 0.06 & 0.03 & 0.04 & 0.10 & 0.30 & 0.10 & 0.19 & 0.43 \\
\hline Rimini & 24 & 0.13 & 0.05 & 0.06 & 0.25 & 0.57 & 0.16 & 0.28 & 0.92 \\
\hline Roma & 281 & 0.11 & 0.07 & 0.04 & 0.86 & 0.44 & 0.15 & 0.19 & 1.30 \\
\hline
\end{tabular}


Table 3 (continued)

\begin{tabular}{|c|c|c|c|c|c|c|c|c|c|}
\hline \multirow[t]{2}{*}{ Municipality } & \multirow[t]{2}{*}{ OMI } & \multicolumn{4}{|c|}{ Share of foreign-born } & \multicolumn{4}{|c|}{ Entropy Index } \\
\hline & & Mean & S.D. & Min & Max & Mean & S.D. & Min & $\operatorname{Max}$ \\
\hline Rovigo & 10 & 0.05 & 0.03 & 0.03 & 0.12 & 0.28 & 0.14 & 0.13 & 0.60 \\
\hline Salerno & 22 & 0.04 & 0.01 & 0.02 & 0.08 & 0.21 & 0.07 & 0.10 & 0.36 \\
\hline Sassari & 9 & 0.04 & 0.04 & 0.01 & 0.12 & 0.21 & 0.17 & 0.07 & 0.56 \\
\hline Savona & 6 & 0.07 & 0.03 & 0.04 & 0.12 & 0.35 & 0.14 & 0.21 & 0.52 \\
\hline Siena & 25 & 0.09 & 0.04 & 0.05 & 0.19 & 0.40 & 0.14 & 0.20 & 0.76 \\
\hline Siracusa & 16 & 0.06 & 0.03 & 0.03 & 0.12 & 0.29 & 0.12 & 0.15 & 0.48 \\
\hline Sondrio & 12 & 0.06 & 0.03 & 0.02 & 0.12 & 0.28 & 0.13 & 0.10 & 0.53 \\
\hline Taranto & 23 & 0.04 & 0.07 & 0.01 & 0.33 & 0.15 & 0.14 & 0.06 & 0.64 \\
\hline Teramo & 28 & 0.08 & 0.02 & 0.03 & 0.14 & 0.41 & 0.09 & 0.17 & 0.66 \\
\hline Terni & 34 & 0.08 & 0.04 & 0.03 & 0.21 & 0.38 & 0.16 & 0.13 & 0.89 \\
\hline Torino & 40 & 0.13 & 0.05 & 0.07 & 0.28 & 0.55 & 0.19 & 0.35 & 1.10 \\
\hline Trani & 3 & 0.03 & 0.01 & 0.02 & 0.04 & 0.16 & 0.06 & 0.13 & 0.23 \\
\hline Trapani & 13 & 0.04 & 0.02 & 0.02 & 0.09 & 0.19 & 0.09 & 0.11 & 0.43 \\
\hline Treviso & 4 & 0.13 & 0.02 & 0.11 & 0.16 & 0.58 & 0.12 & 0.44 & 0.69 \\
\hline Trieste & 8 & 0.18 & 0.04 & 0.14 & 0.25 & 0.73 & 0.15 & 0.57 & 1.02 \\
\hline Udine & 4 & 0.17 & 0.03 & 0.13 & 0.21 & 0.71 & 0.12 & 0.55 & 0.84 \\
\hline Urbino & 7 & 0.11 & 0.06 & 0.01 & 0.17 & 0.47 & 0.25 & 0.05 & 0.73 \\
\hline Varese & 13 & 0.12 & 0.04 & 0.08 & 0.18 & 0.51 & 0.16 & 0.31 & 0.76 \\
\hline Verbania & 19 & 0.10 & 0.05 & 0.02 & 0.23 & 0.43 & 0.16 & 0.09 & 0.84 \\
\hline Vercelli & 5 & 0.10 & 0.03 & 0.06 & 0.12 & 0.45 & 0.14 & 0.21 & 0.55 \\
\hline Verona & 17 & 0.12 & 0.04 & 0.06 & 0.20 & 0.54 & 0.18 & 0.29 & 0.83 \\
\hline Vibo Valentia & 11 & 0.04 & 0.01 & 0.02 & 0.07 & 0.21 & 0.07 & 0.11 & 0.35 \\
\hline Vicenza & 7 & 0.12 & 0.03 & 0.07 & 0.17 & 0.52 & 0.14 & 0.30 & 0.73 \\
\hline Viterbo & 6 & 0.08 & 0.04 & 0.04 & 0.16 & 0.36 & 0.15 & 0.21 & 0.62 \\
\hline
\end{tabular}

The table reports the number of OMI micro areas, the minimum, maximum, mean and standard deviation of share of migrants and those observed for each municipality. The presented information refers to 2011 


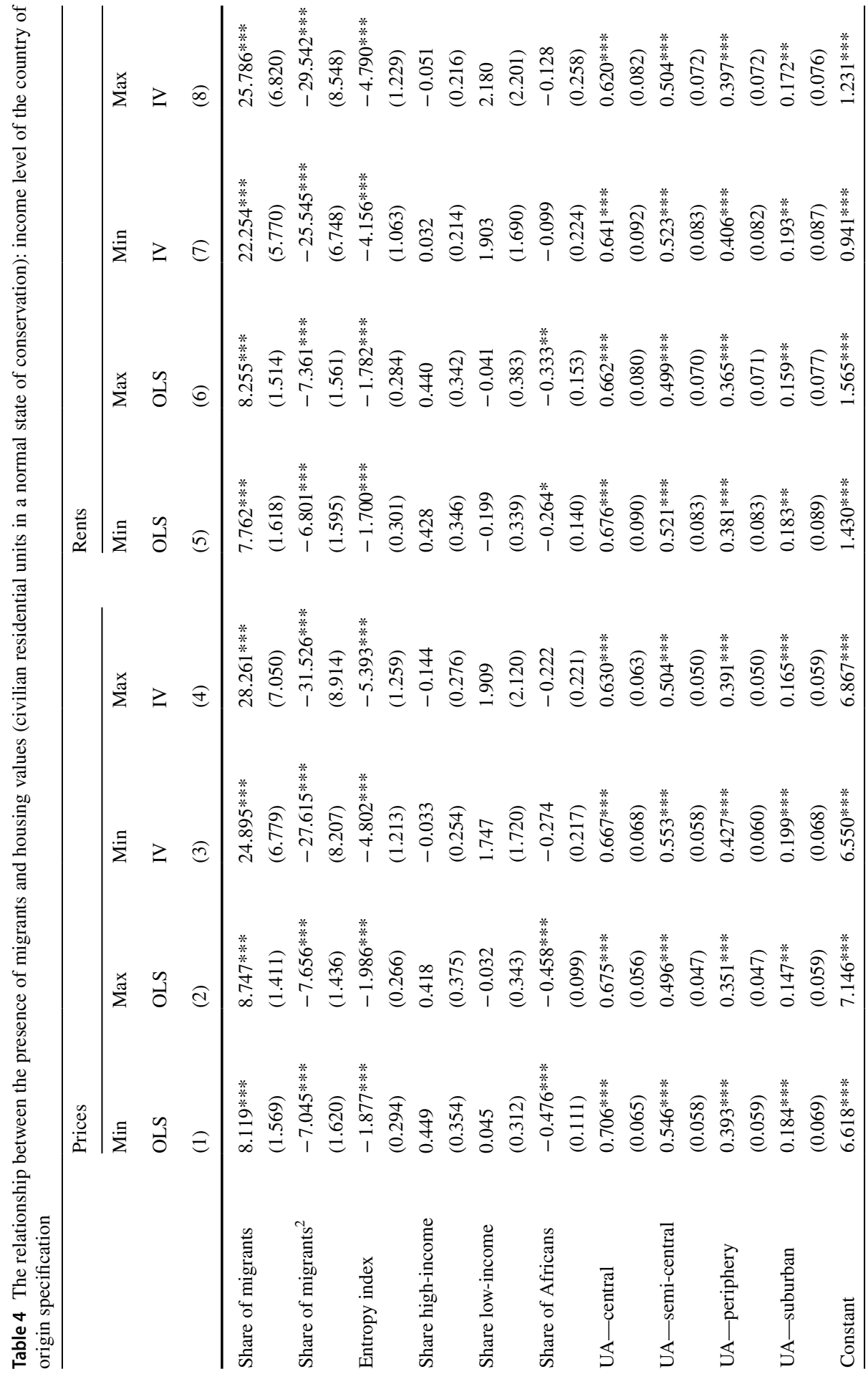




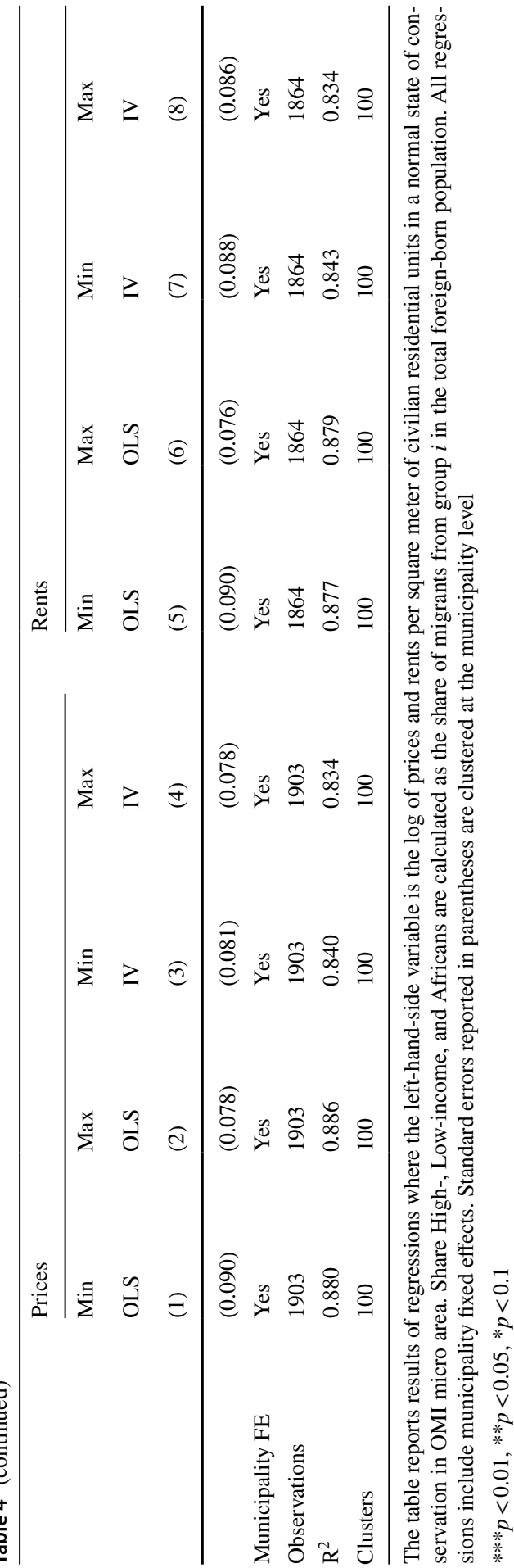




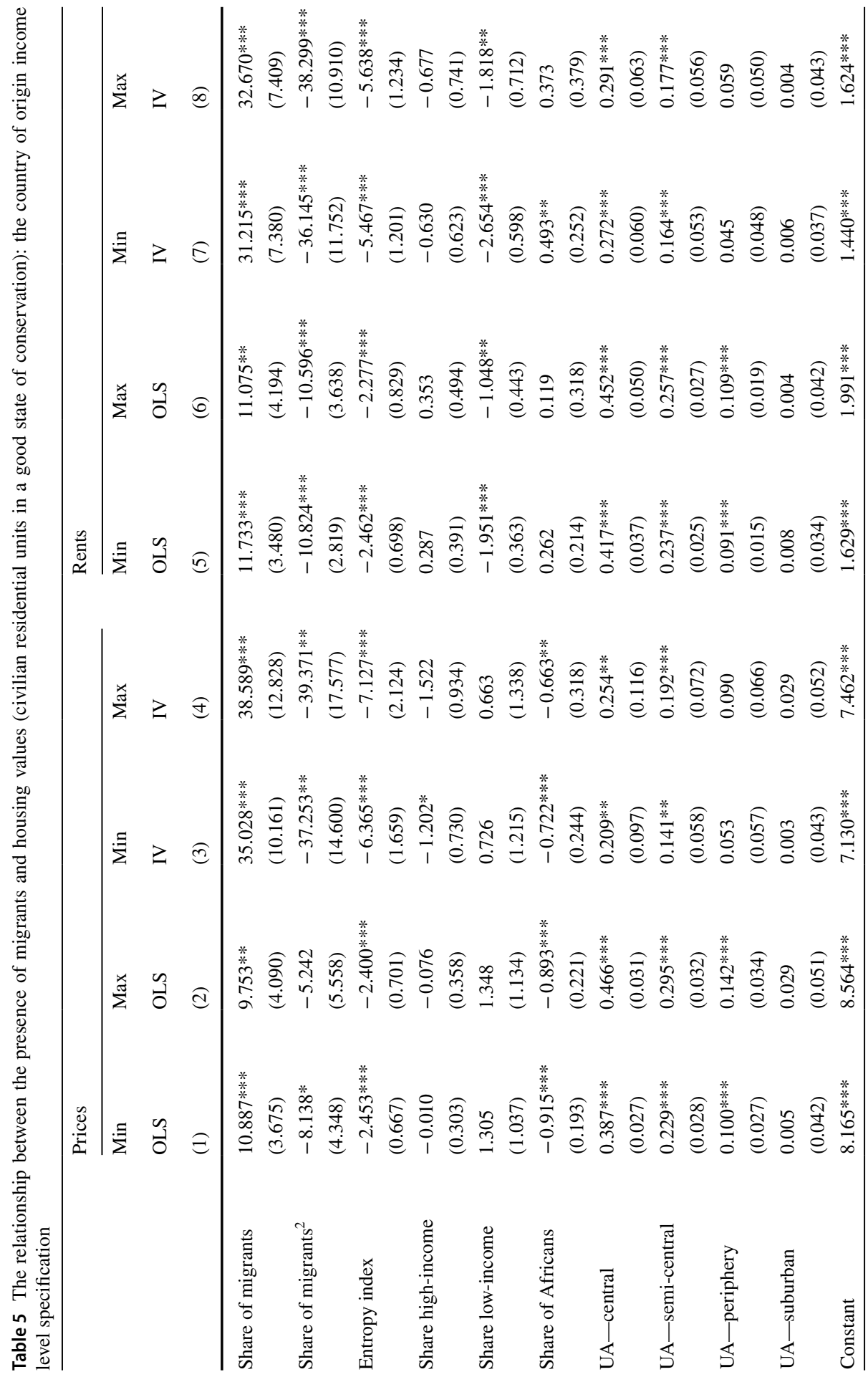




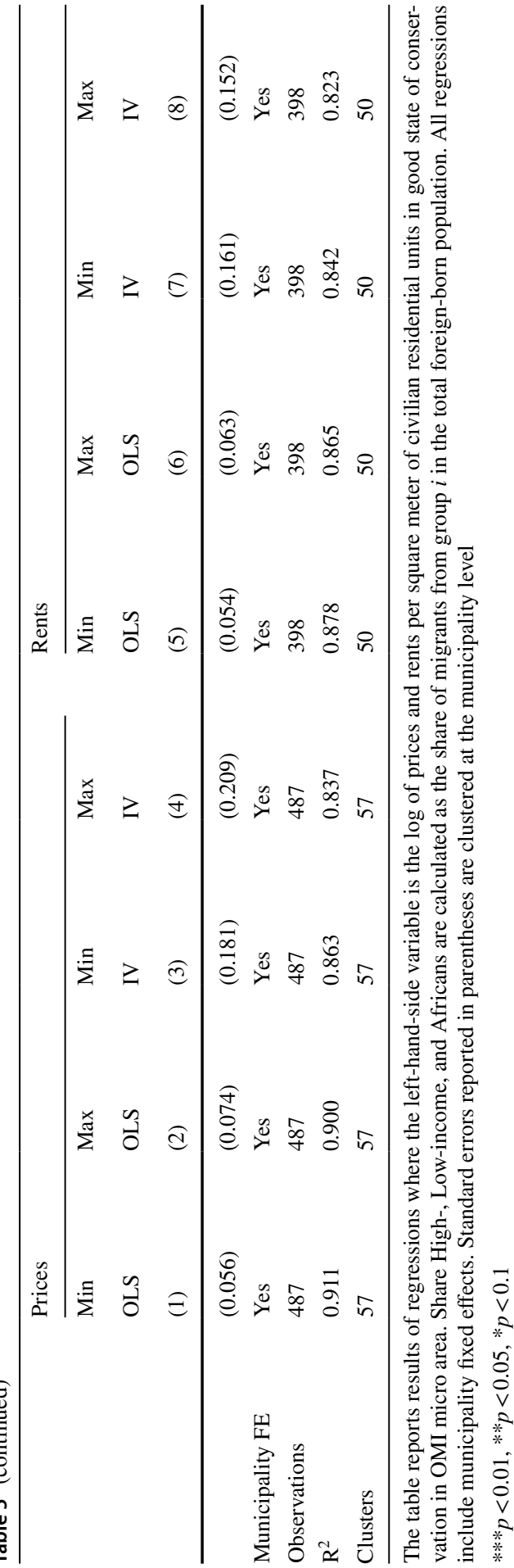




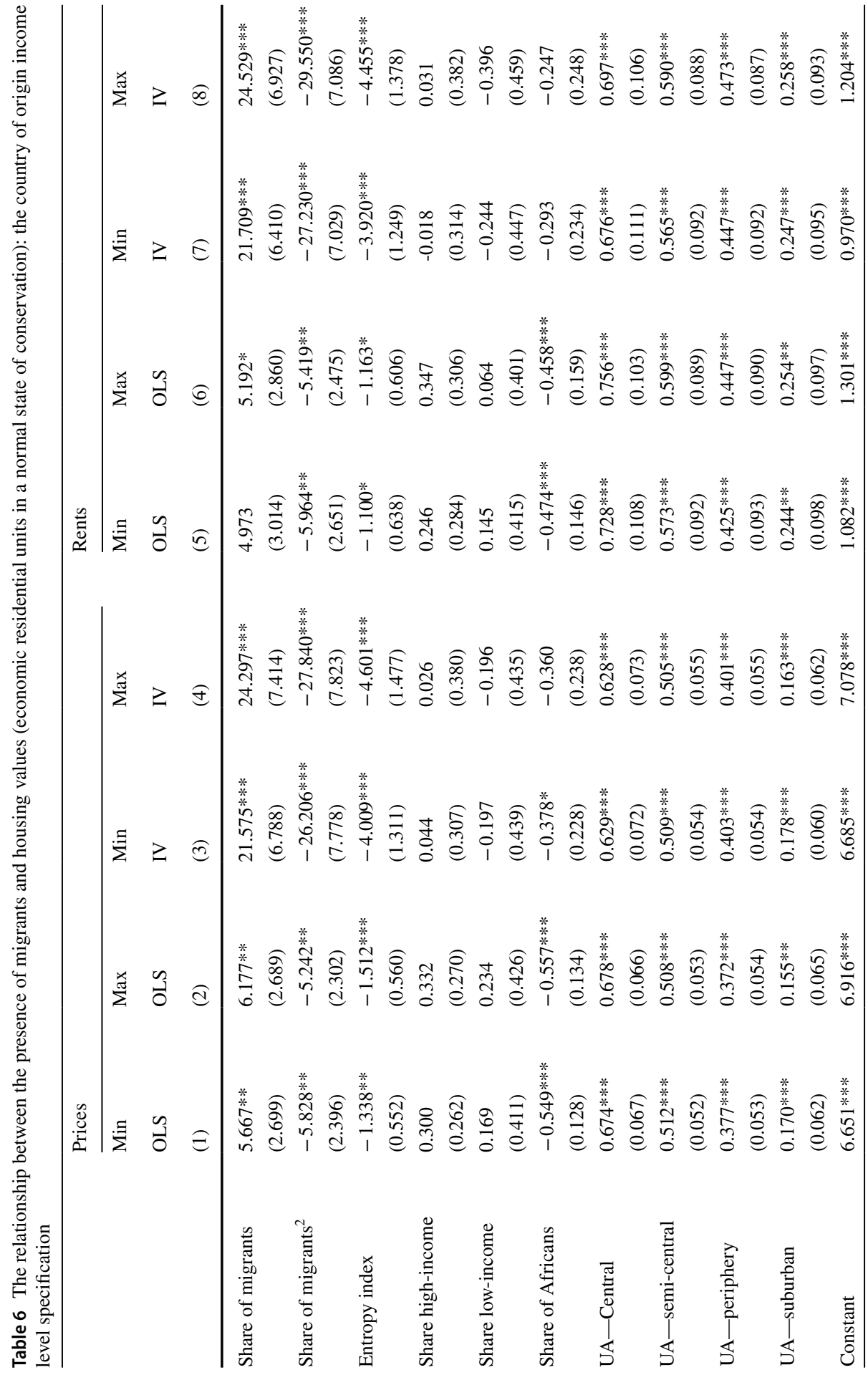




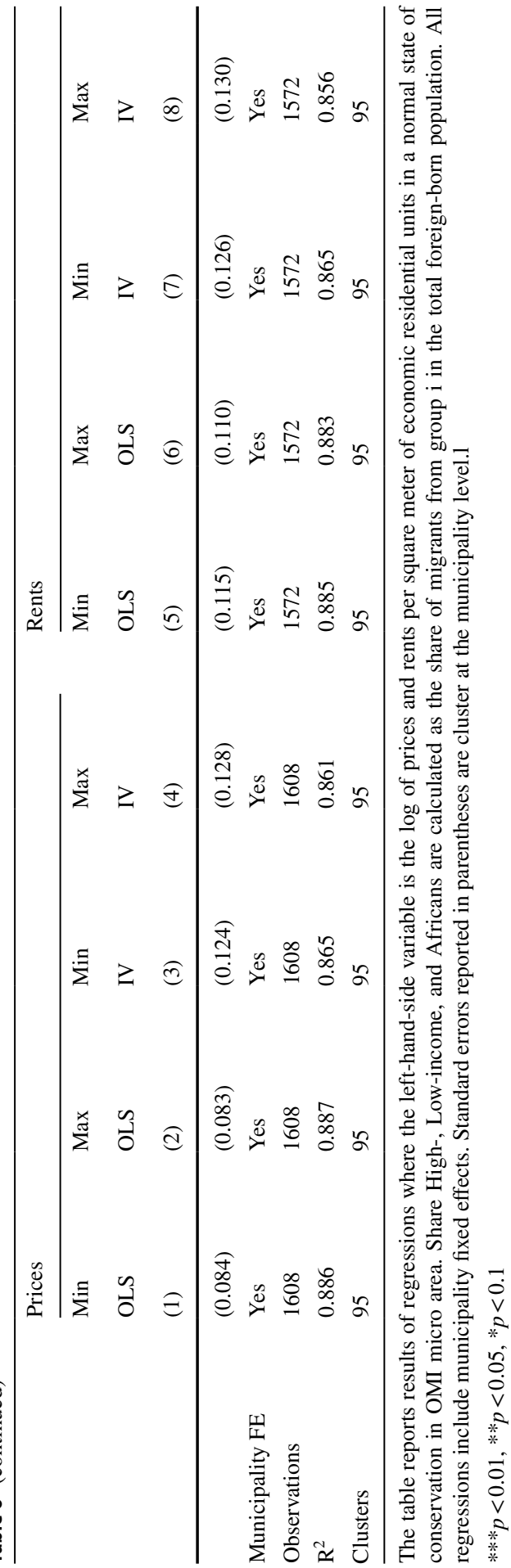




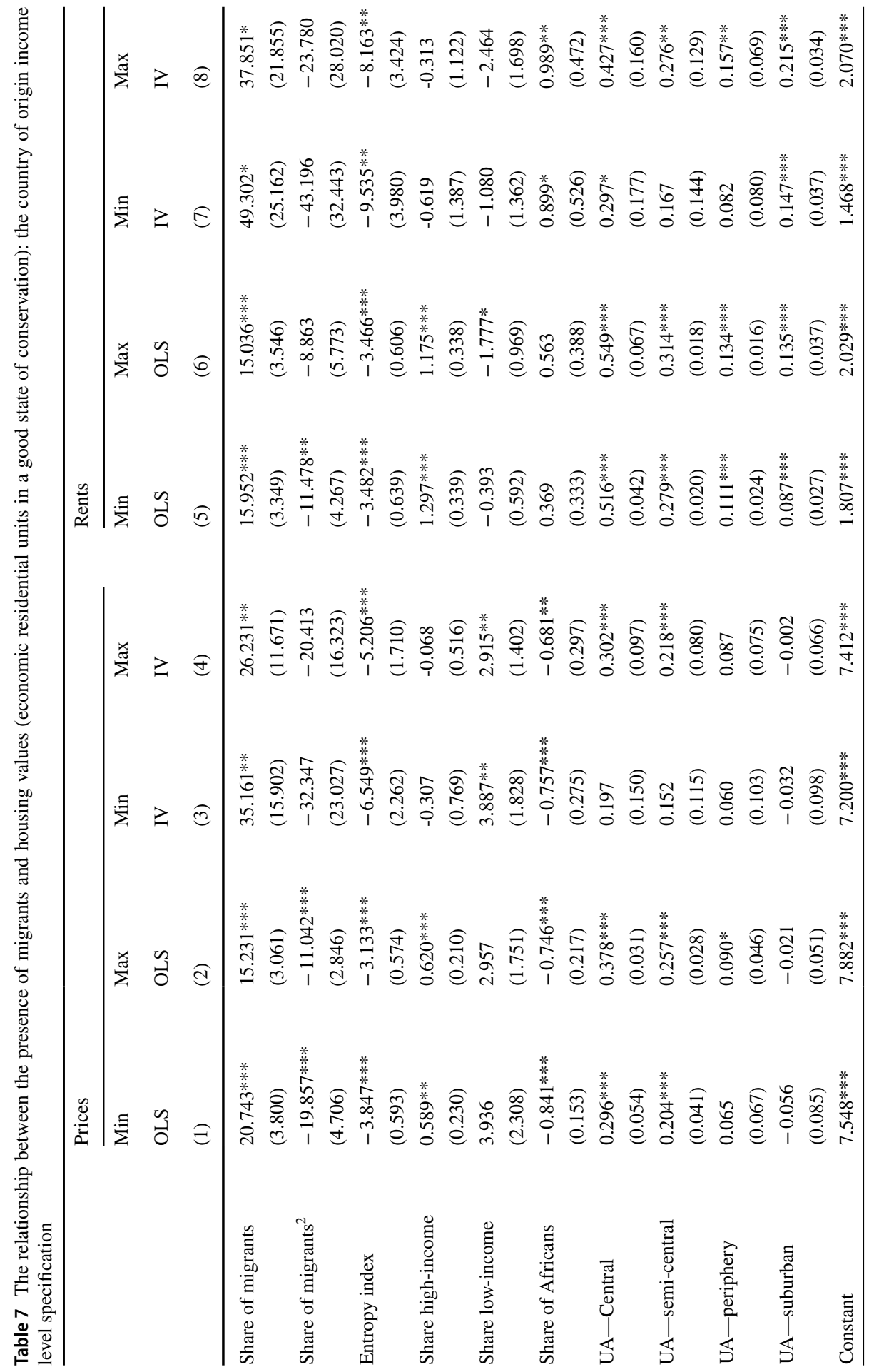




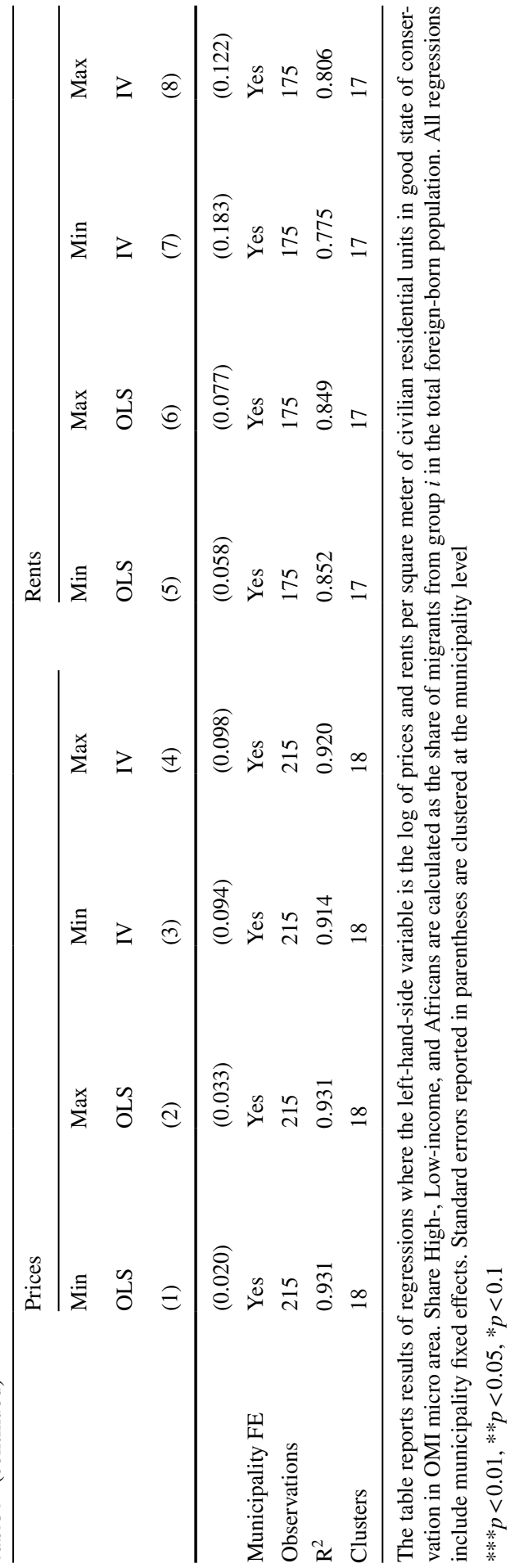




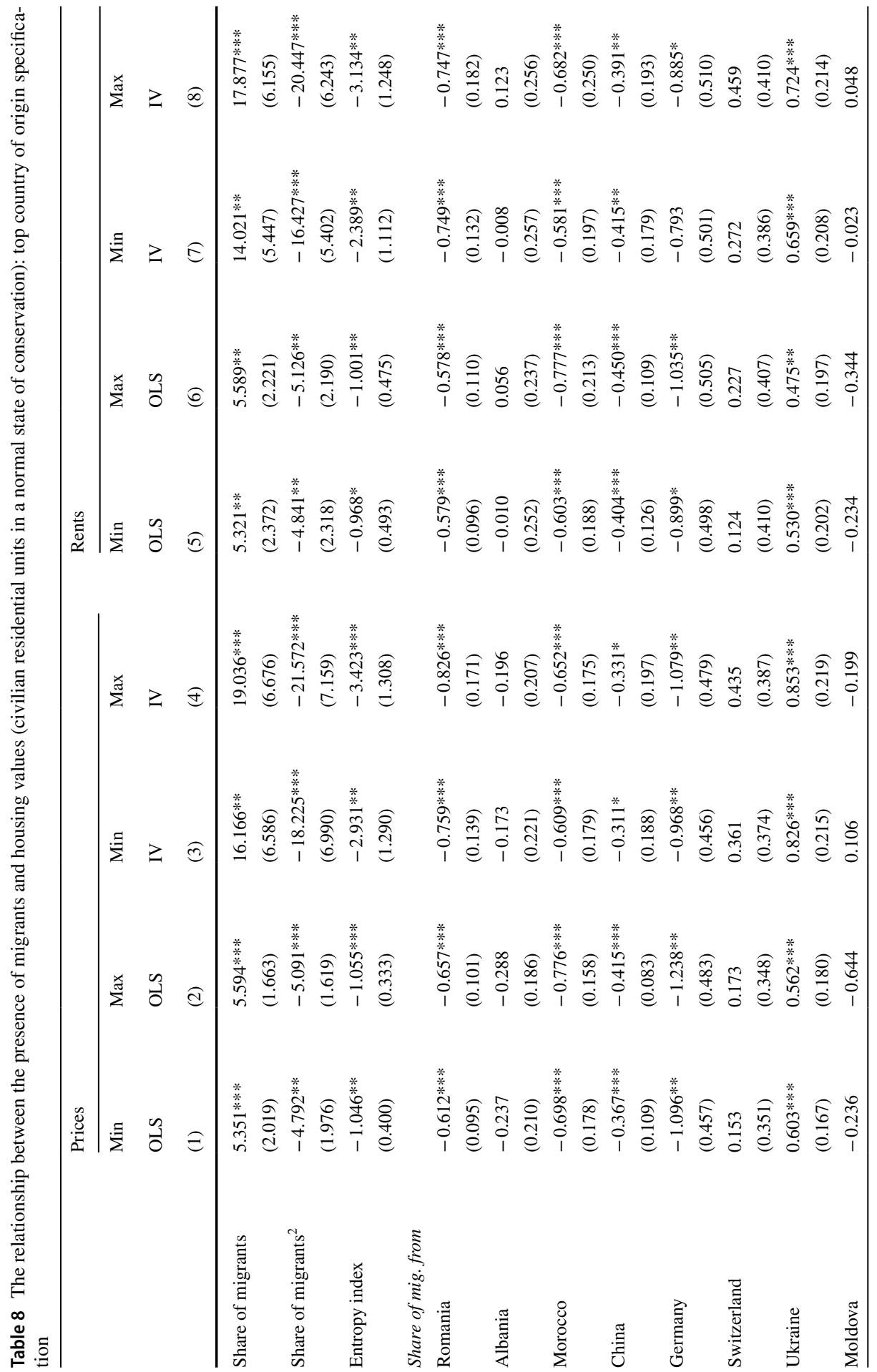




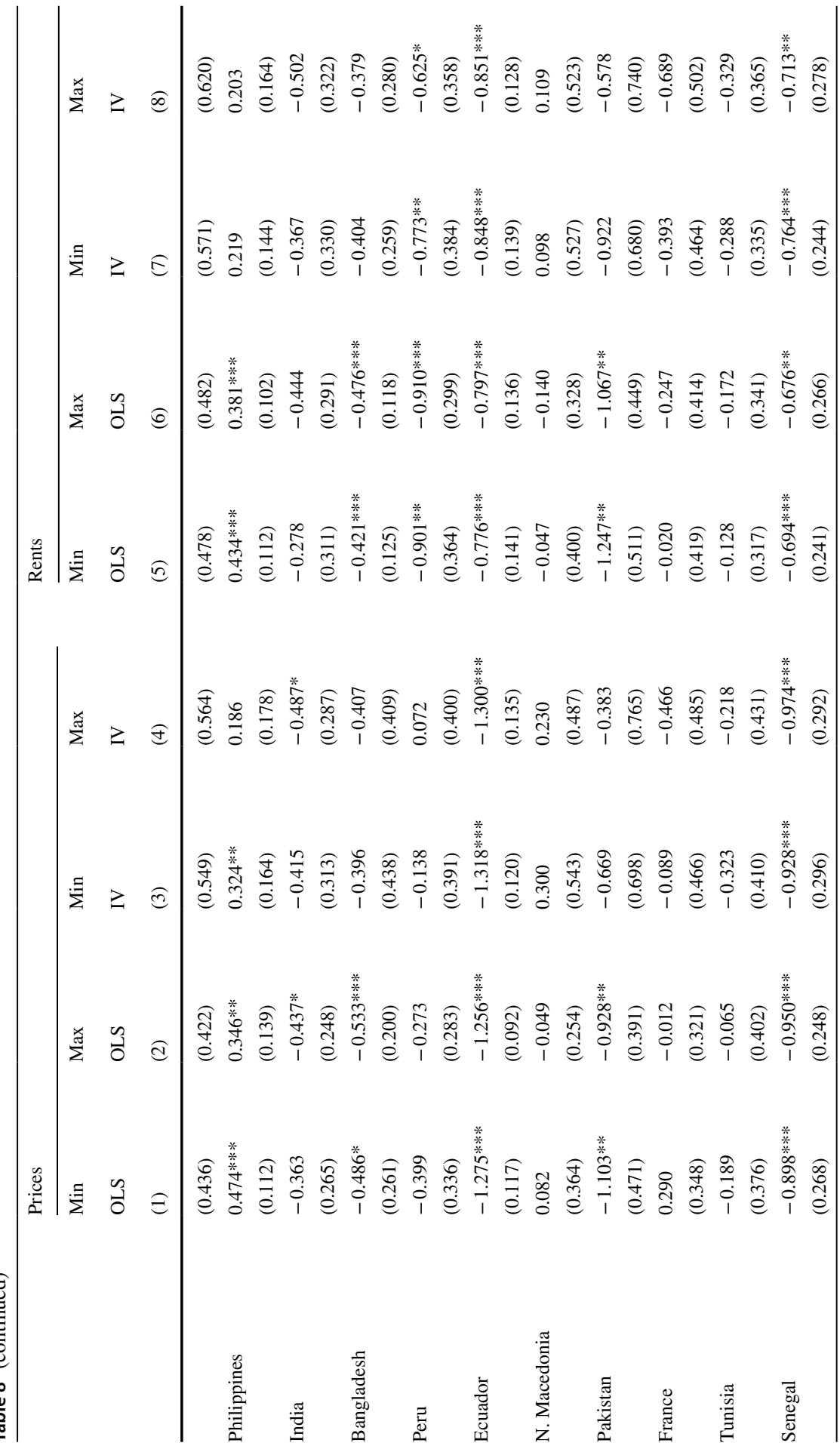




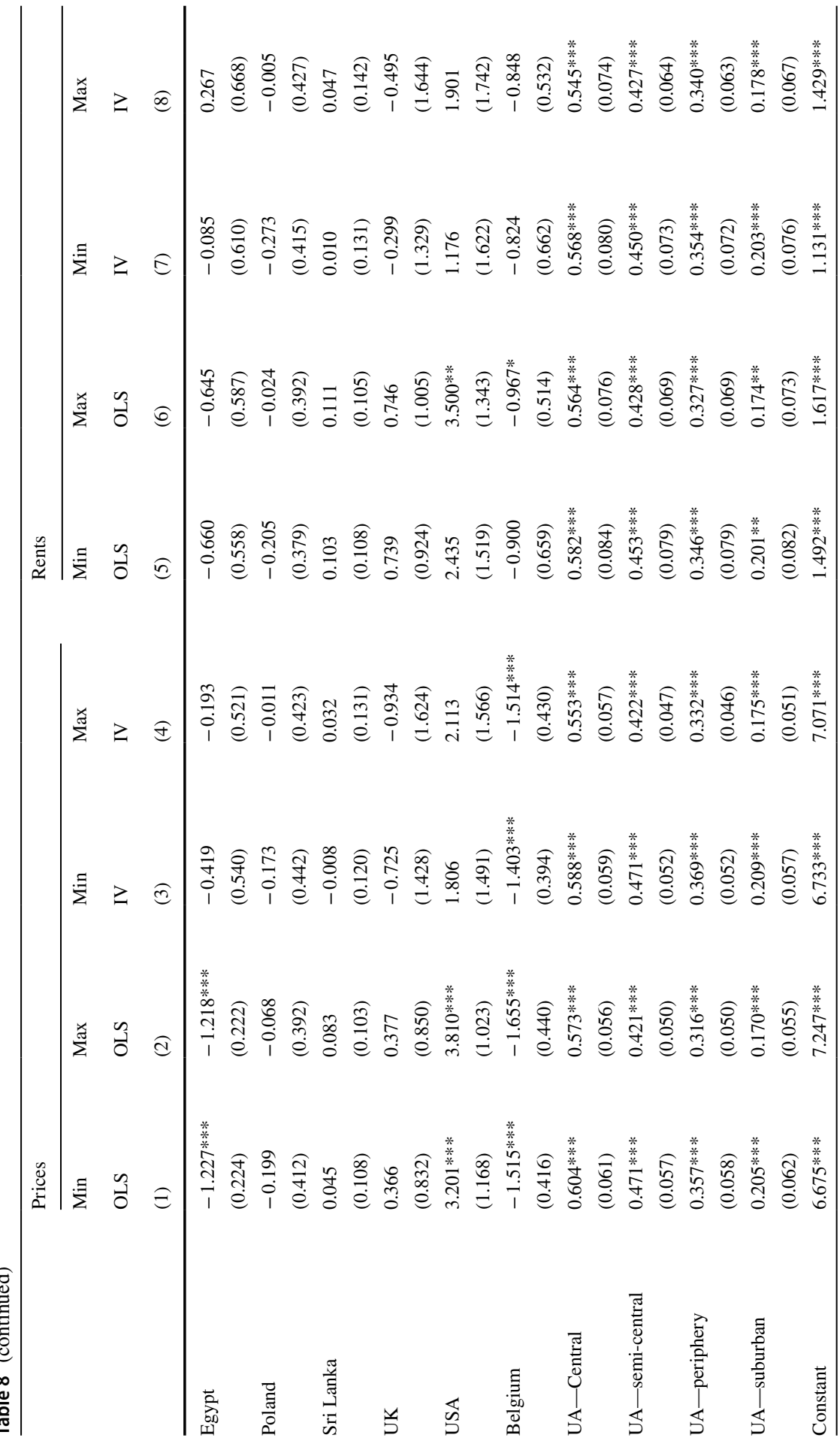




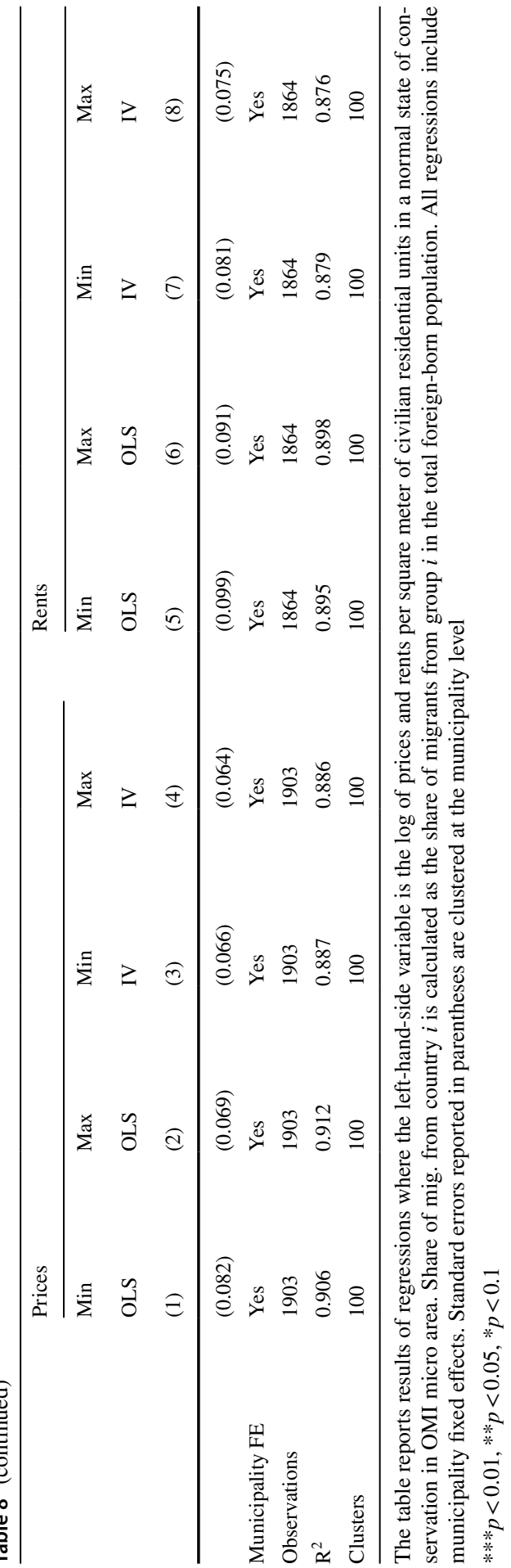




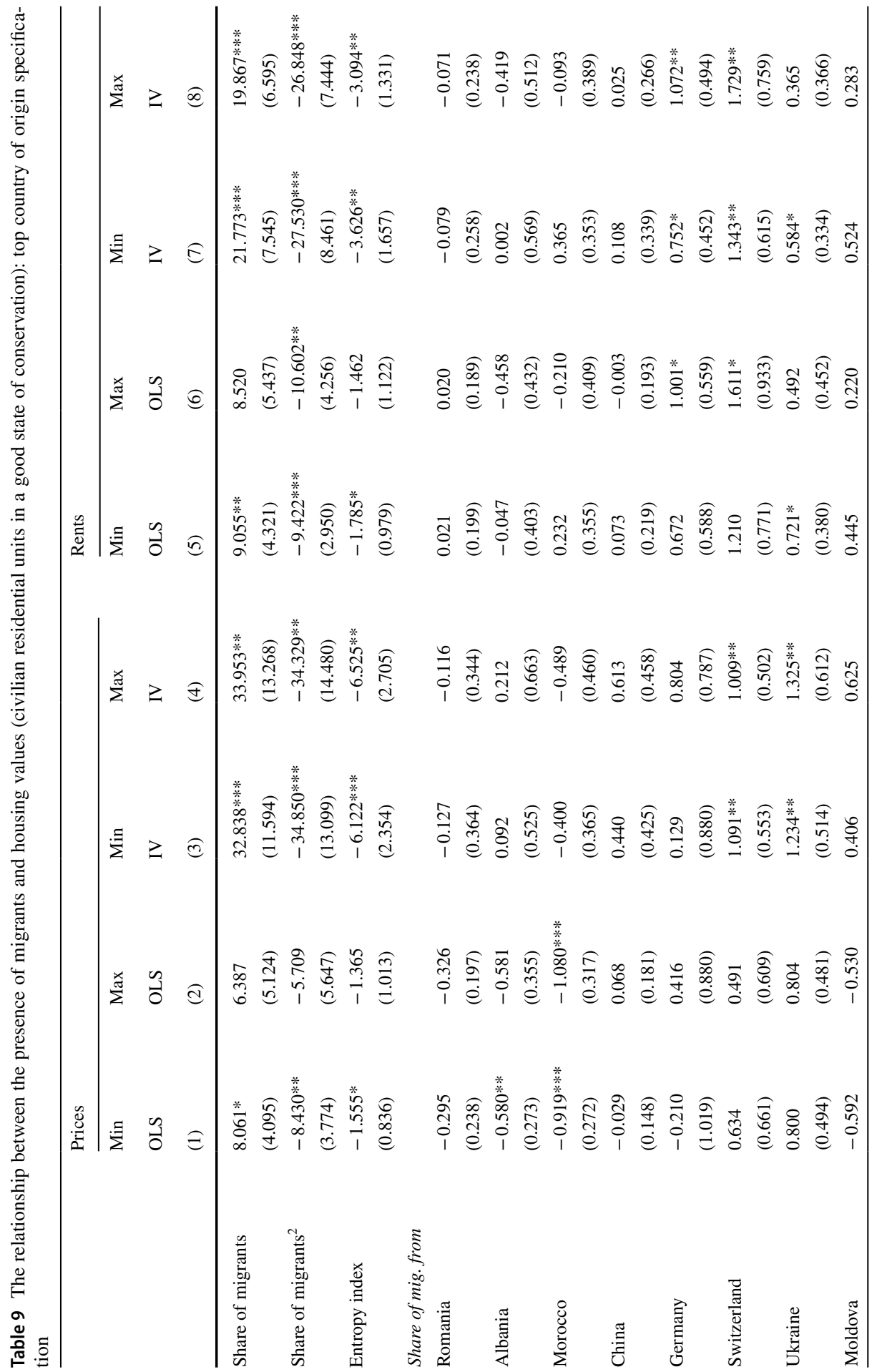




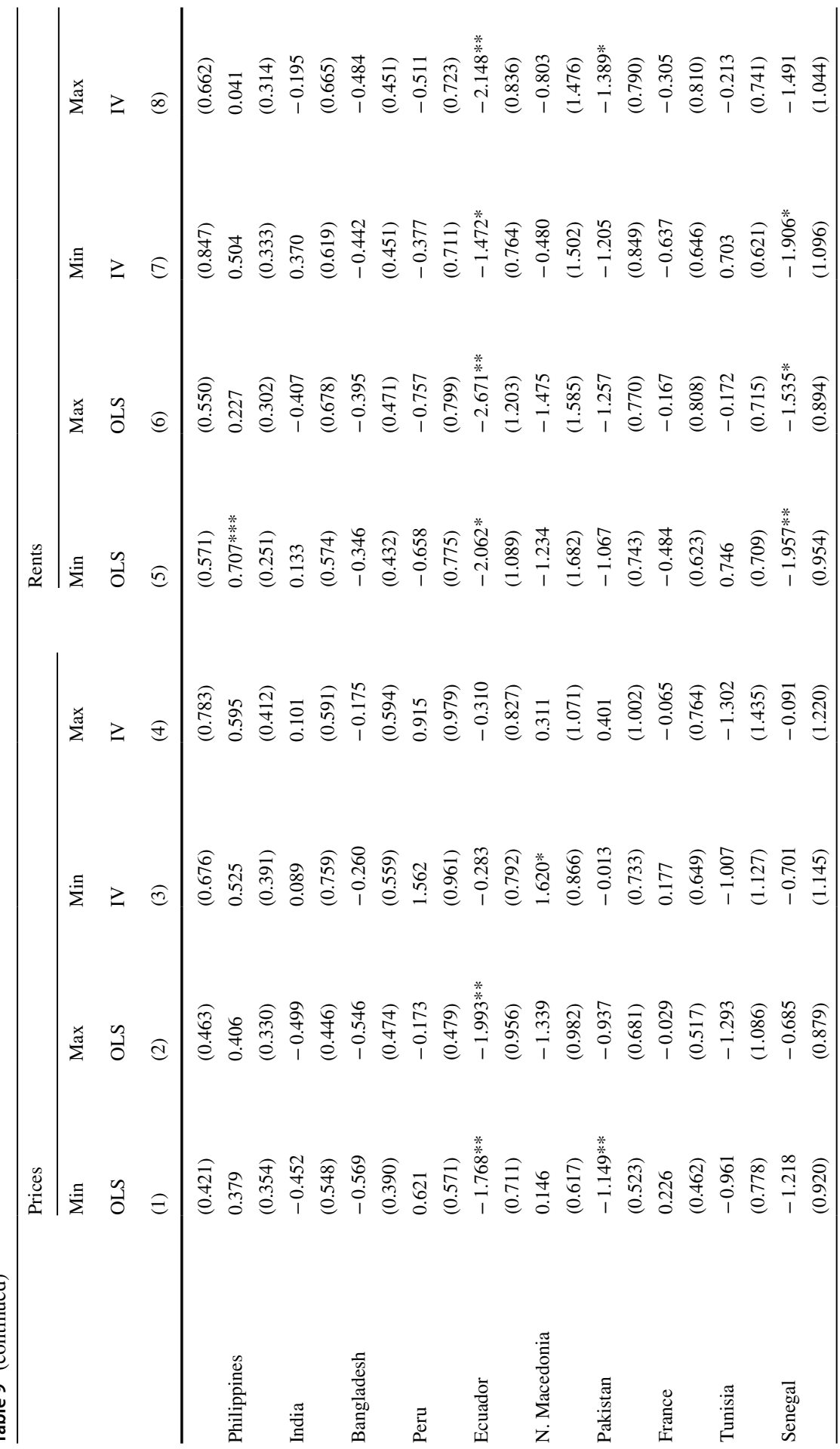




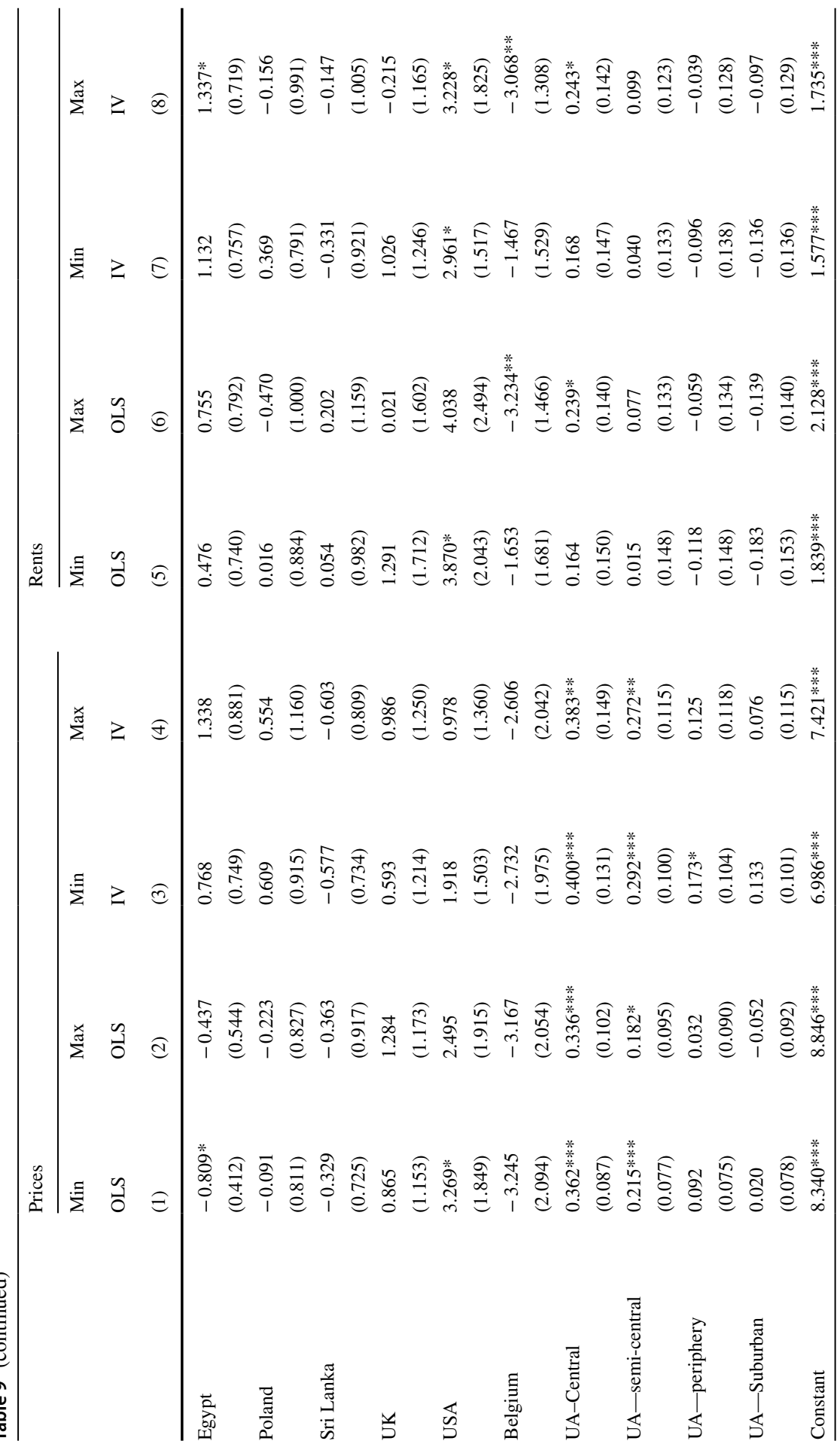




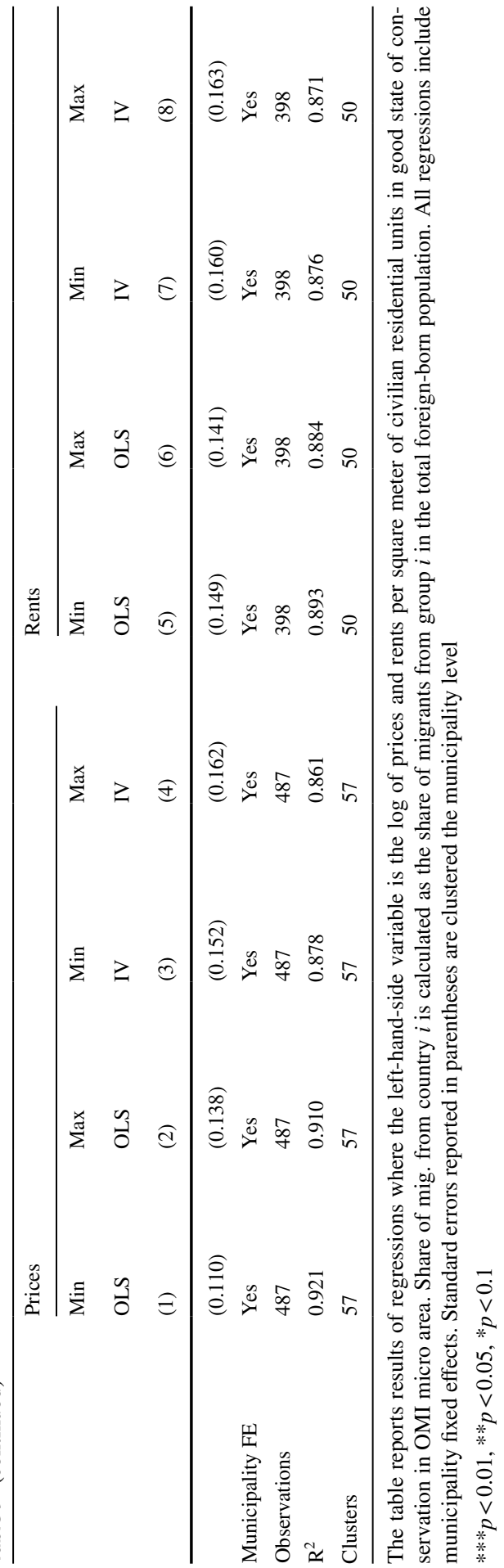




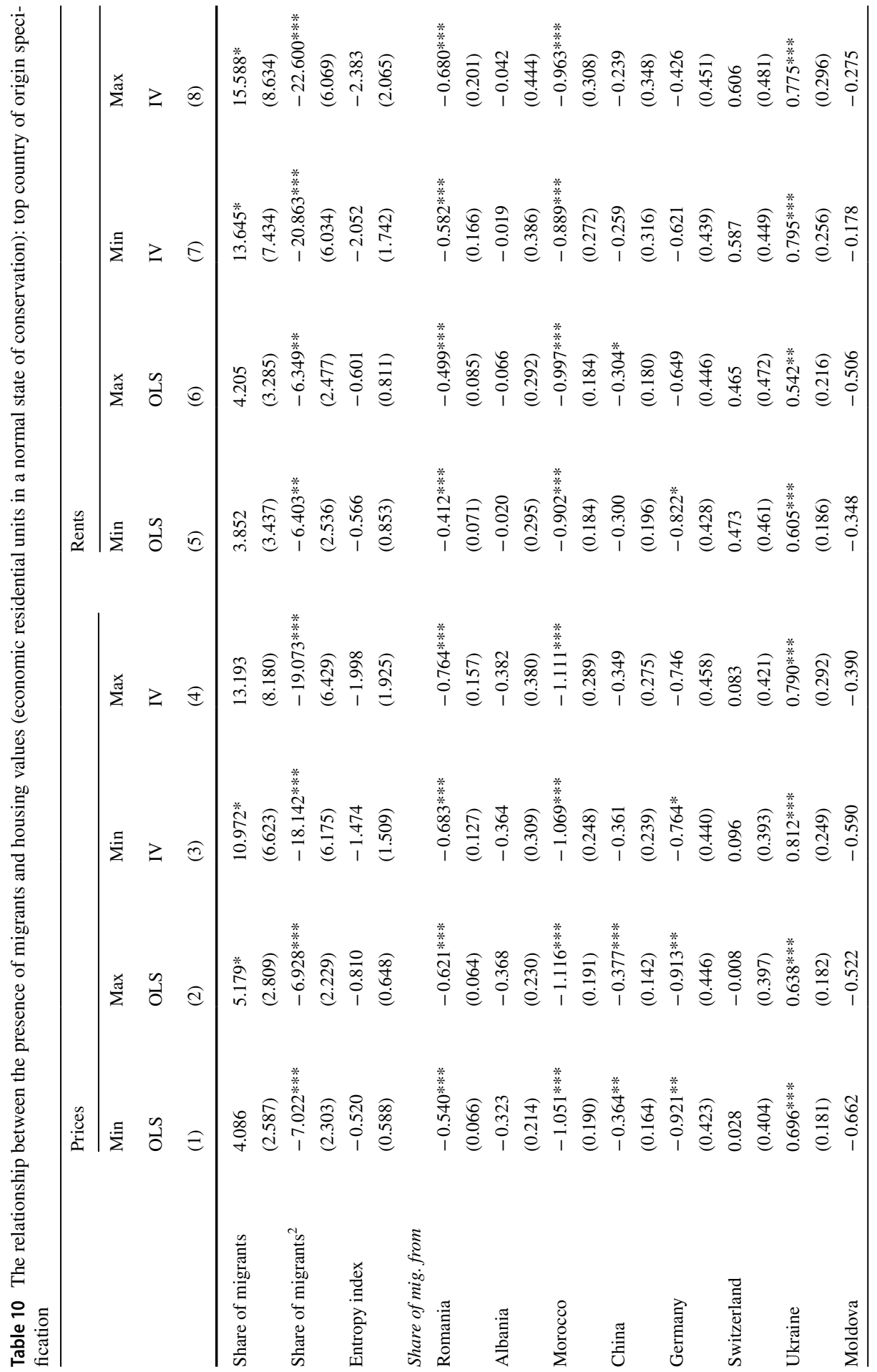




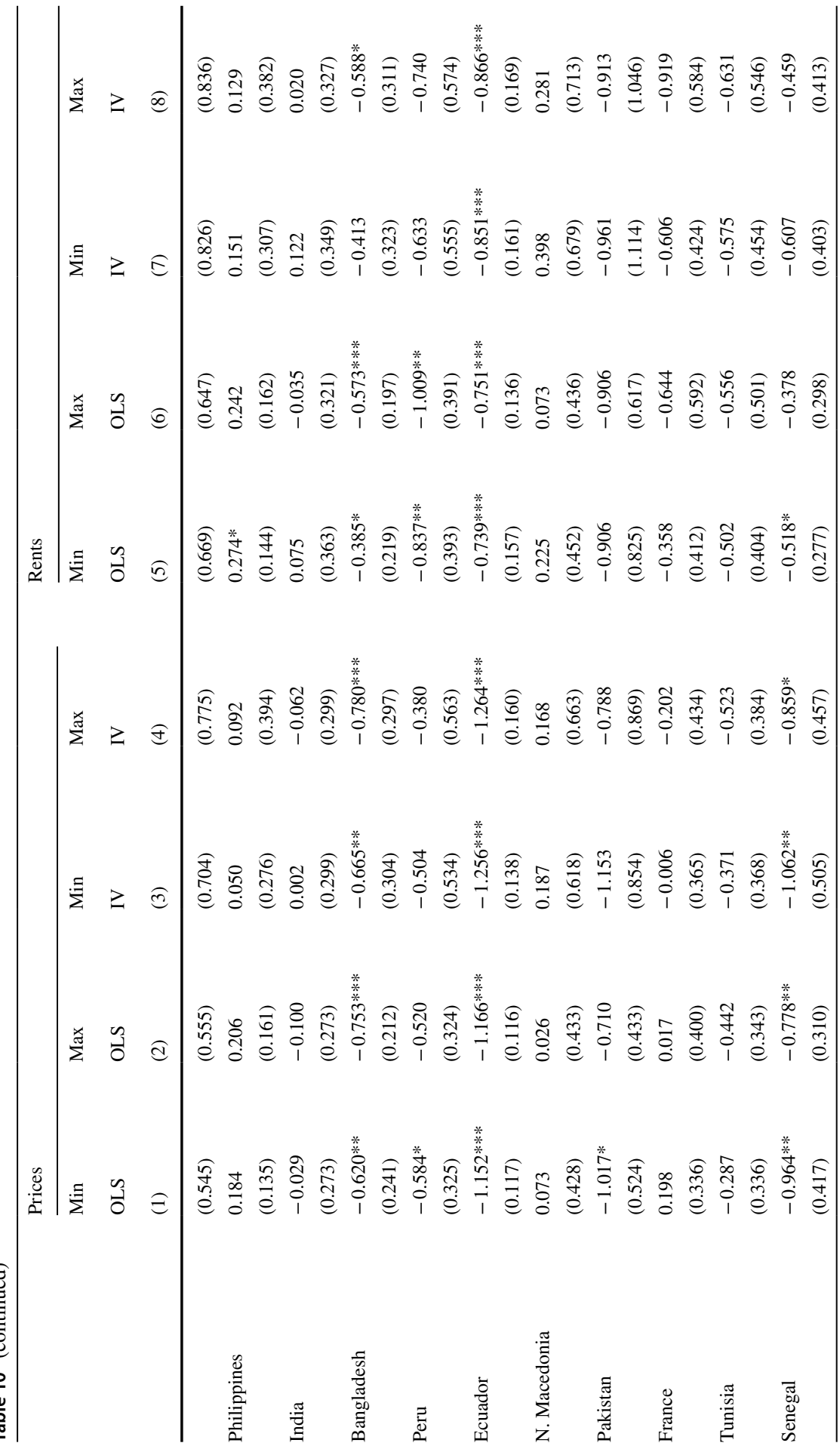




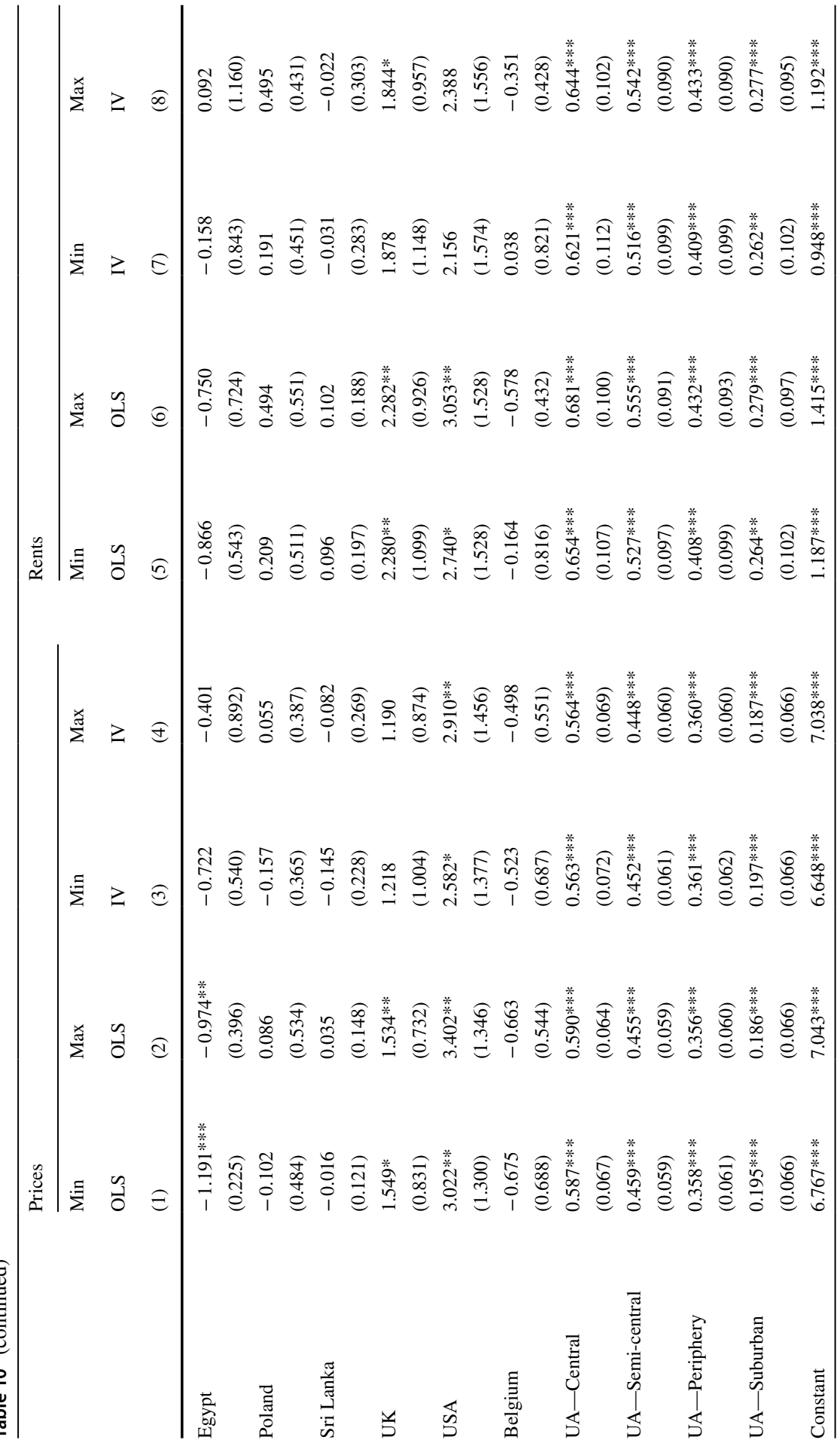




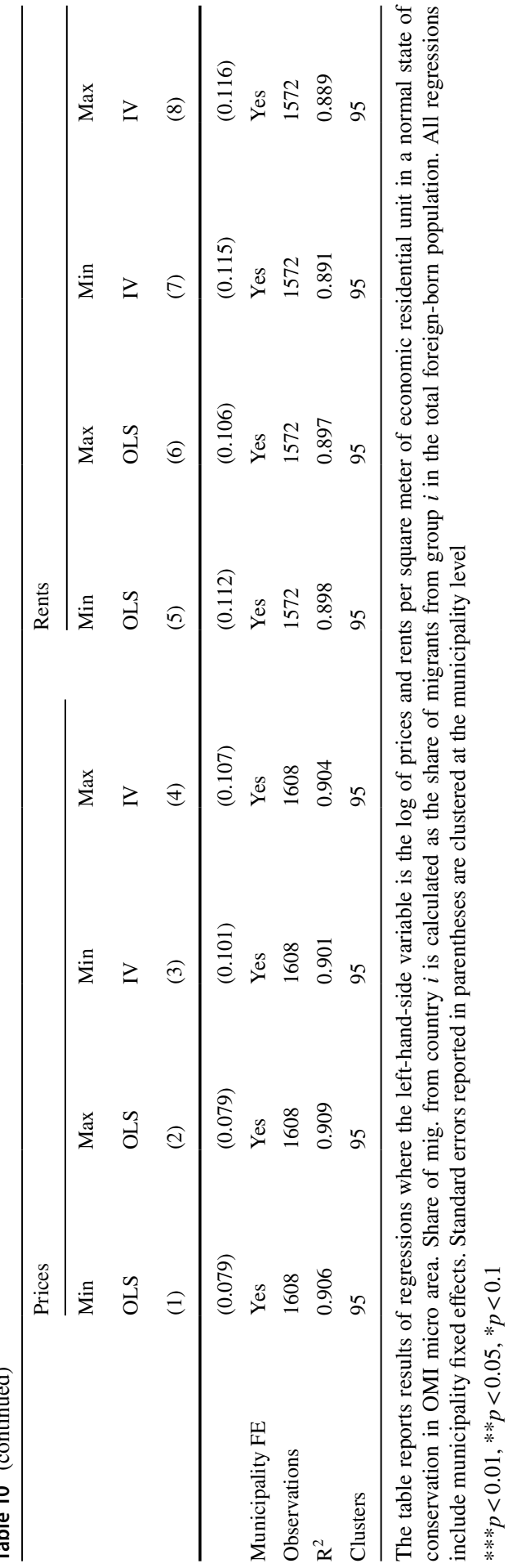




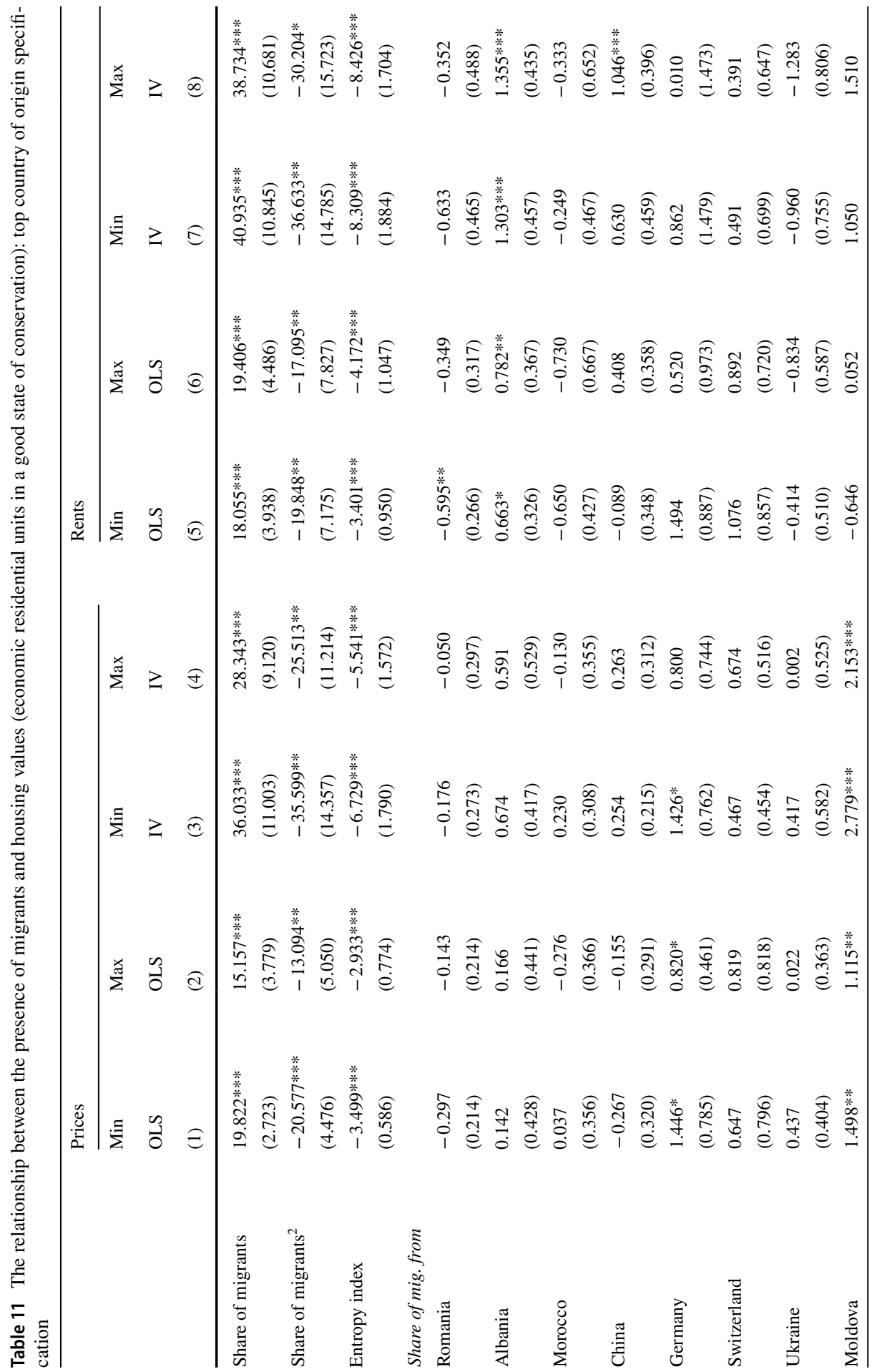




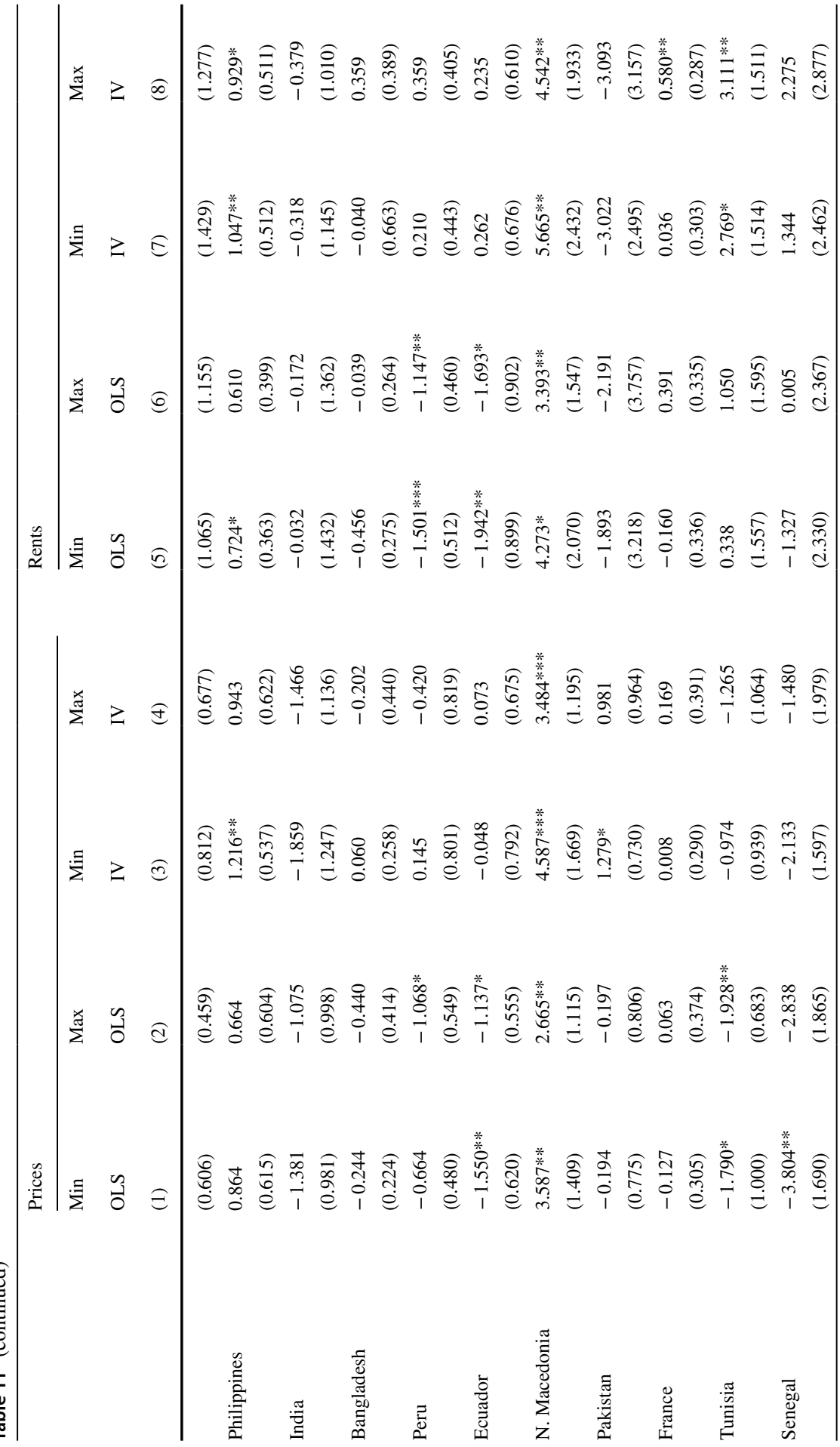




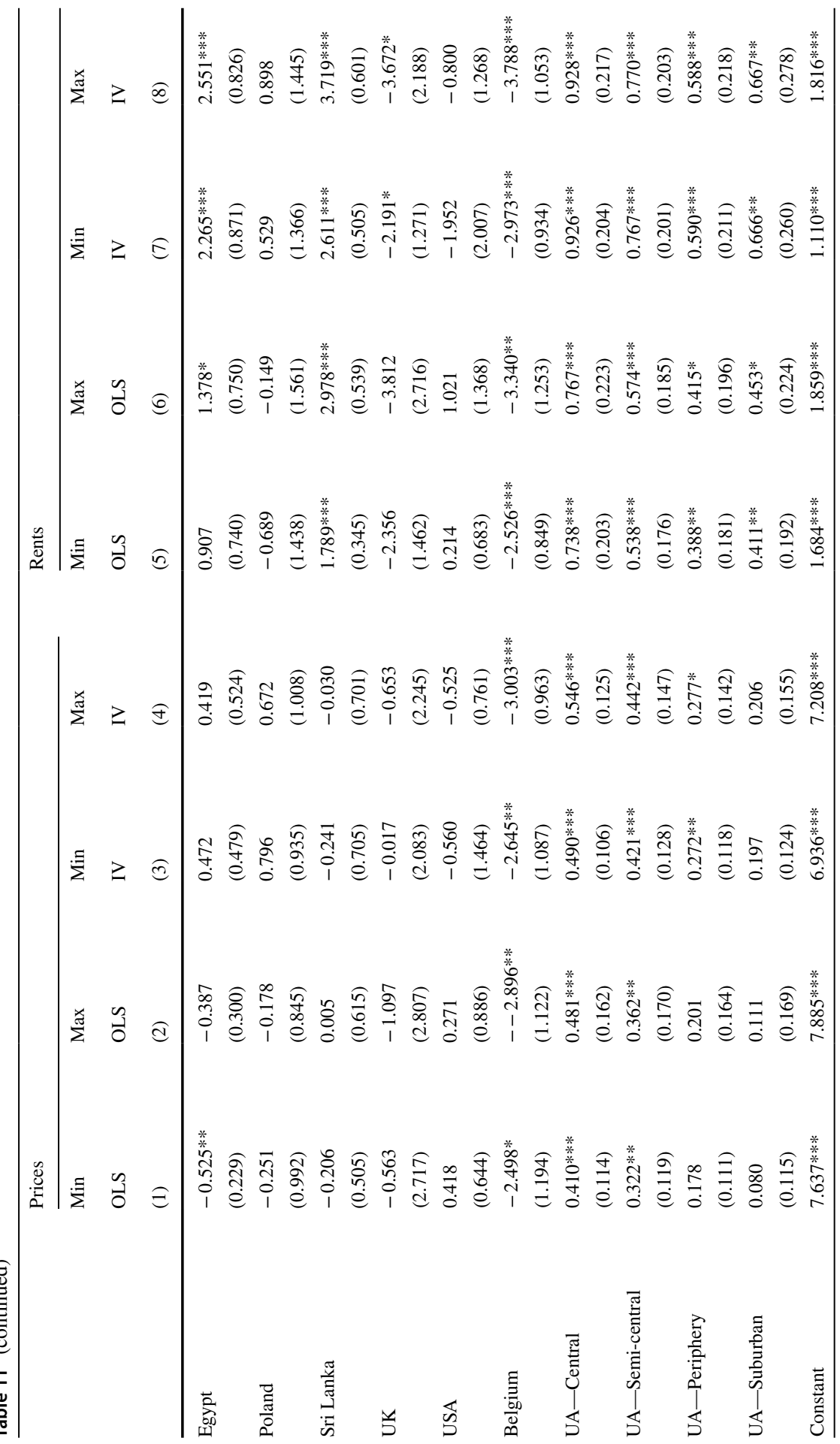




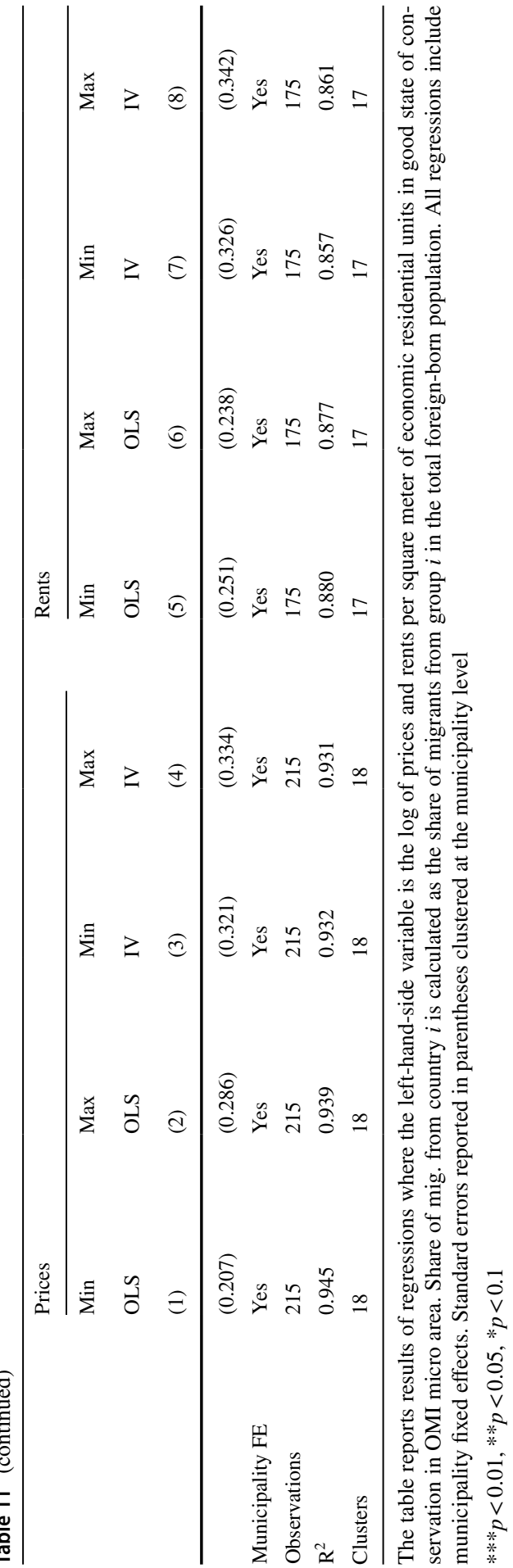




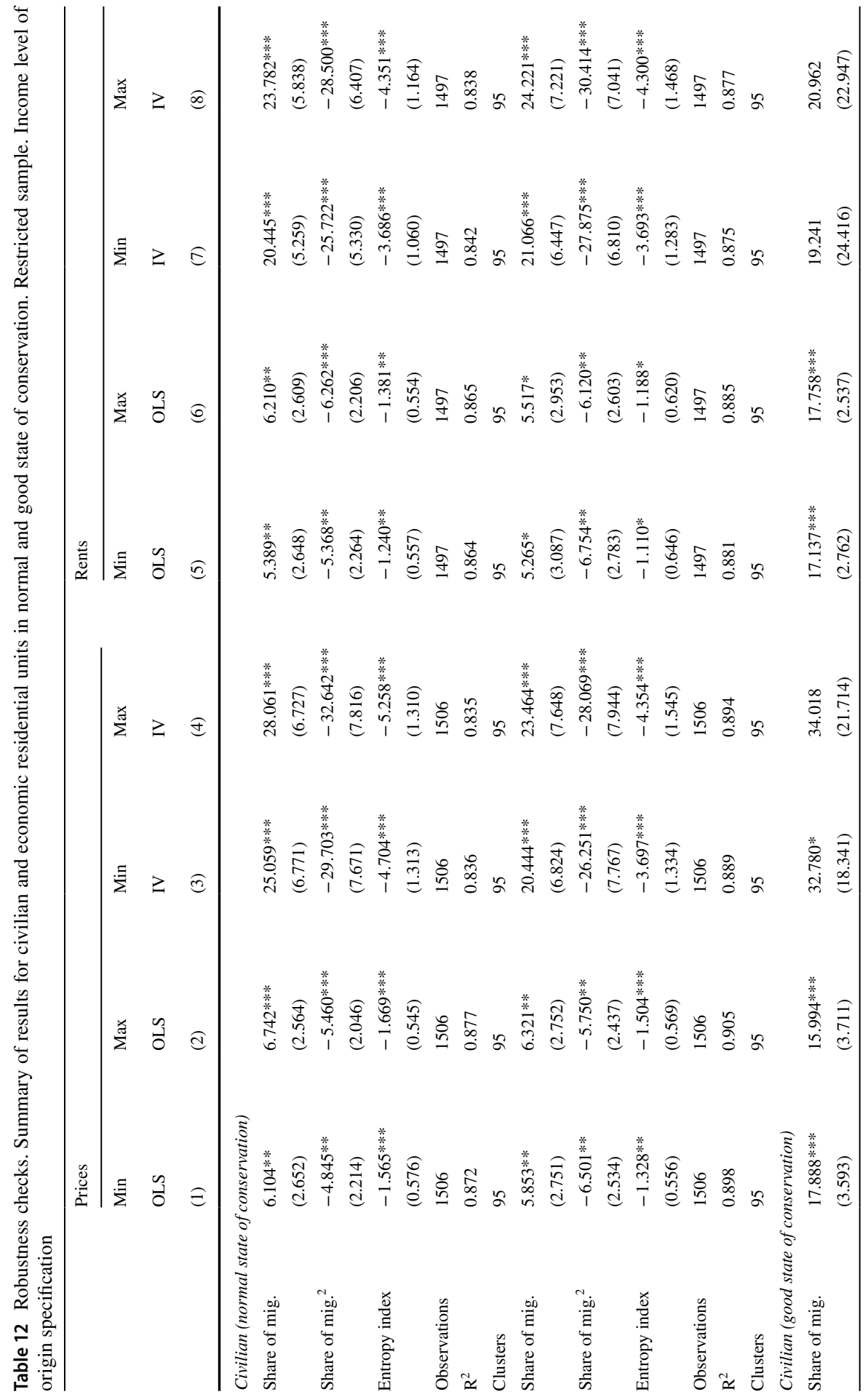




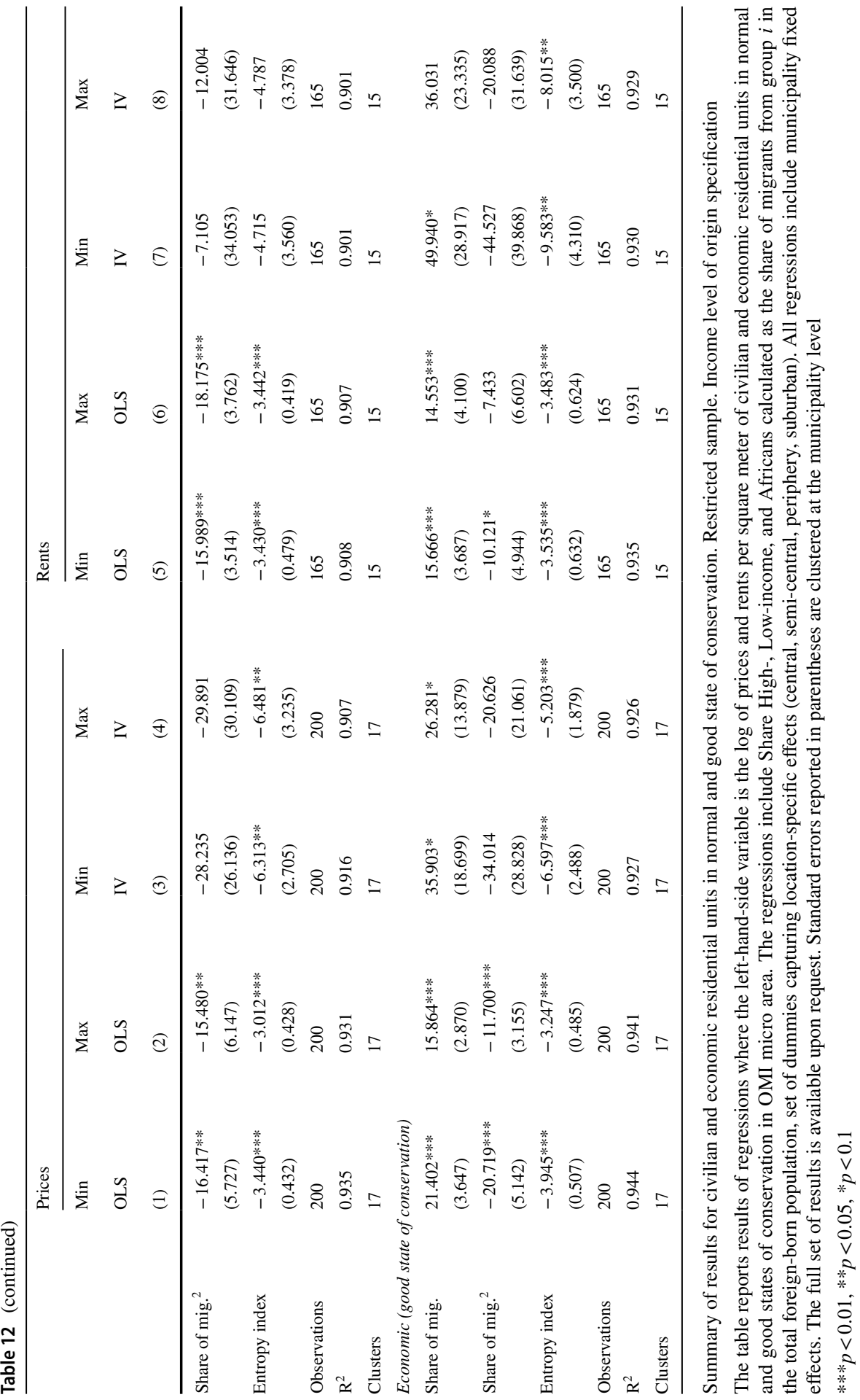




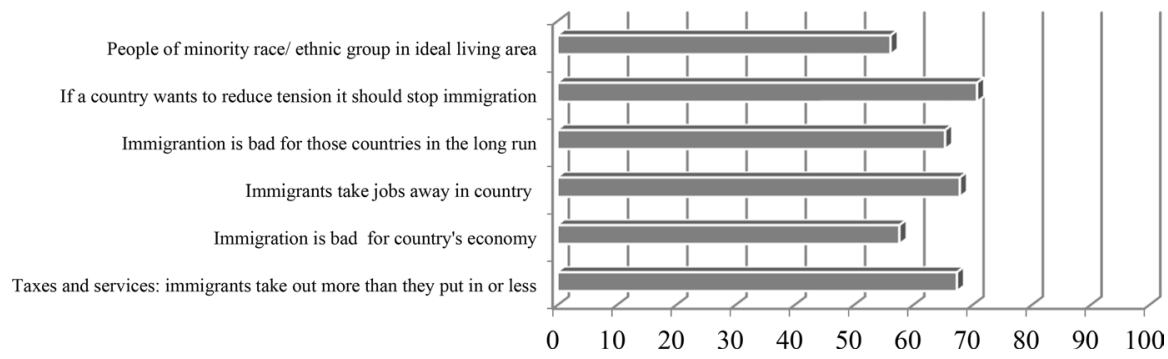

Fig. 1 Attitude towards immigrants. Note: The figure represents the percentage of respondents whose answers indicates negative rather than positive attitudes. Source: European Social Survey (ESS1-2002, ed.6.1), calculation are made by the authors
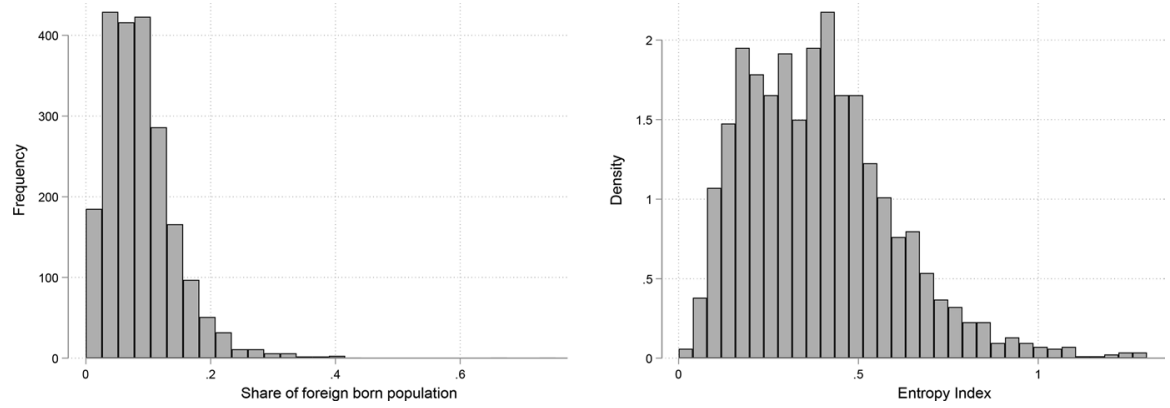

Fig. 2 Distribution of share of migrants and Entropy Index in OMI micro areas. Note: The histograms refer to the share of migrants and the Entropy Index in Italian provincial capitals. The presented information refers to 2011

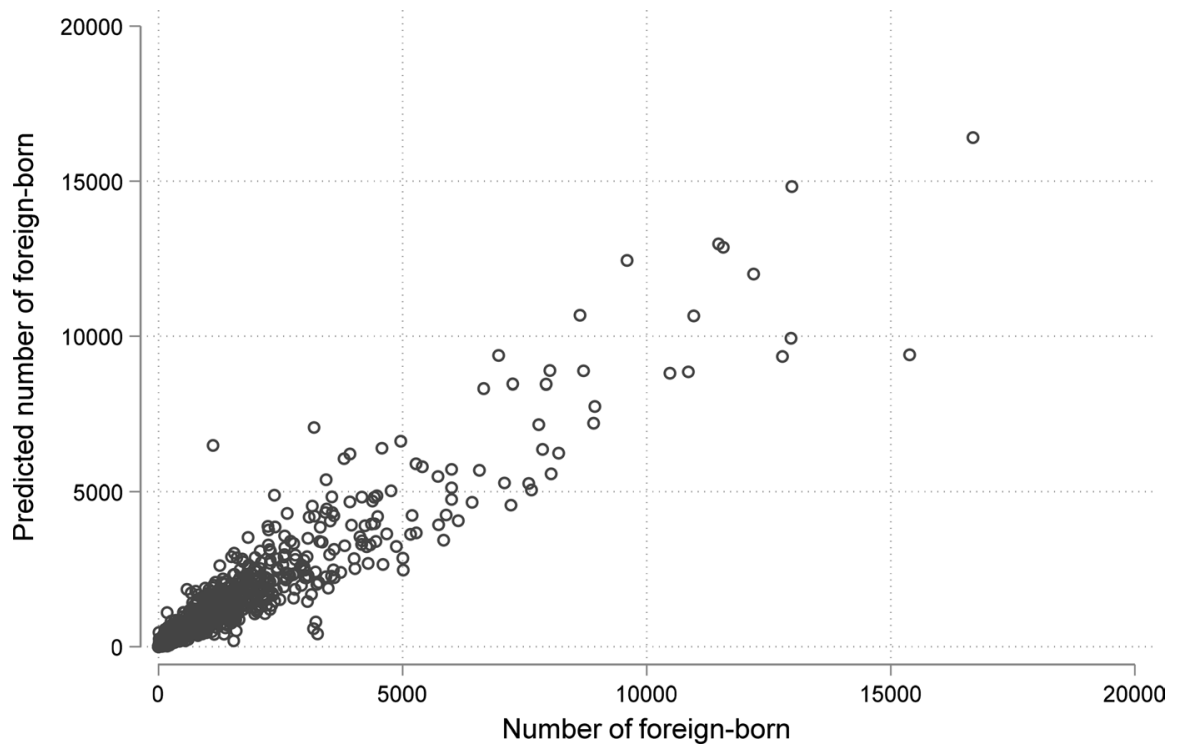

Fig. 3 Actual versus predicted number of immigrants. Note: This graph presents the relationship between the actual and predicted number of immigrants in the neighbourhoods (OMI micro areas) of Italian provincial capitals in 2011 

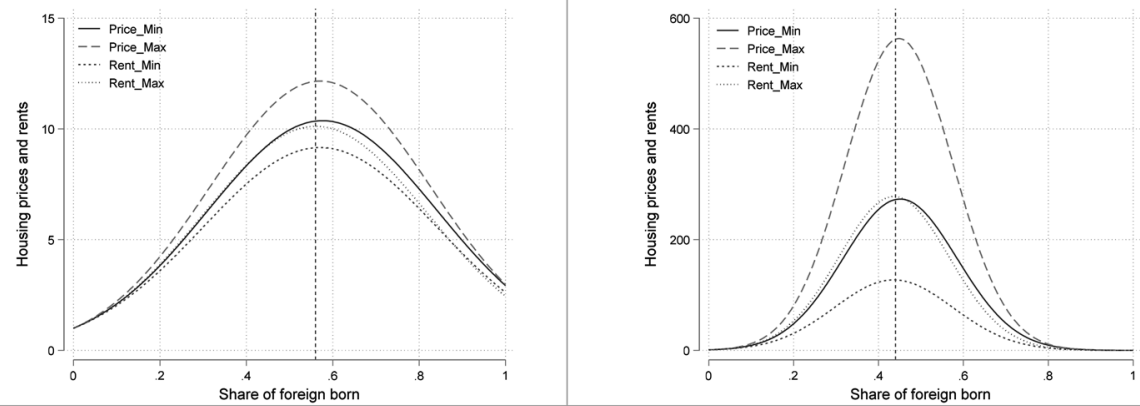

Economic residential units
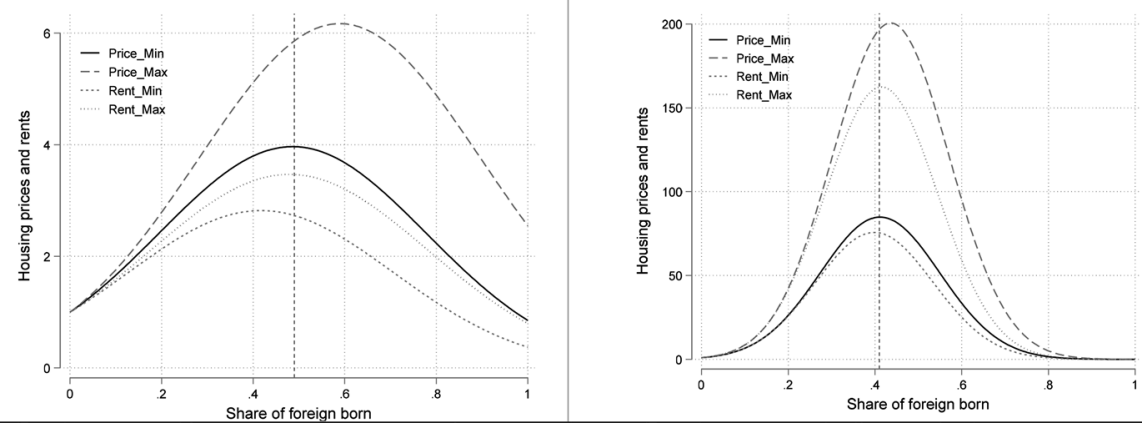

Fig. 4 The non-linear relationship between housing values and concentration of the foreign-born population. Note: The figure presents the relationship between the concentration of migrants and house prices and rents per square meter for units in a normal state of conservation. It is based on coefficients as a share of migrants and its squared term reposted in Tables 4 and 6 . The horizontal axis is the share of immigrants in total population in OMI micro areas. The vertical axis is a log average of housing values price per square meter. The presented information refers to 2011

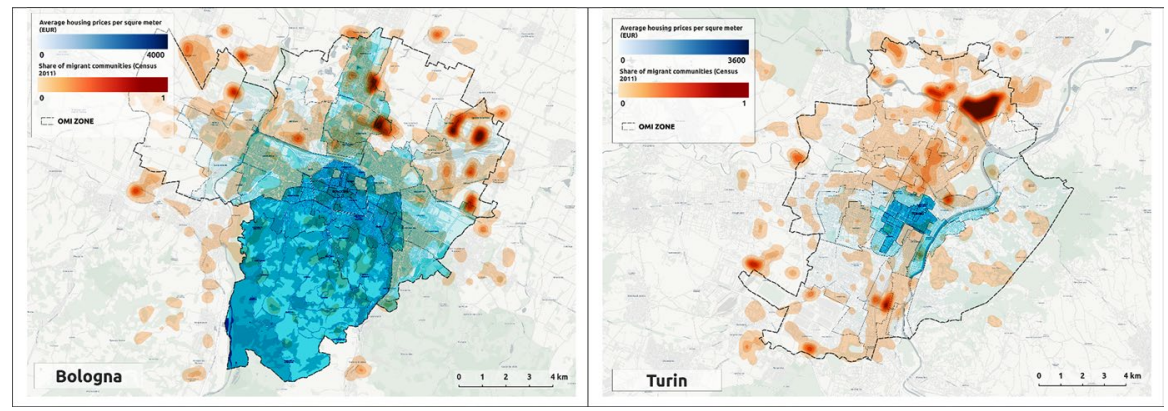

Fig. 5 Average house prices versus migrant share. Note: House prices correspond to average price for a square meter of civilian residential unit by OMI micro areas. Migrant share is presented for territorial unit of $100 \times 100 \mathrm{~m}$. Reference period 2011 


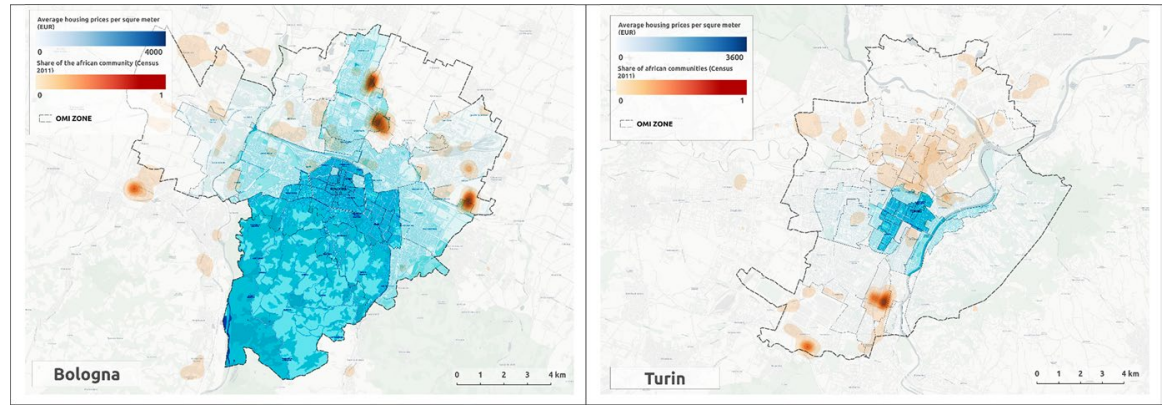

Fig. 6 Average house prices versus Share of African migrants. Note: House prices correspond to the average price for a square meter of civilian residential unit by OMI micro areas. The share of African migrants is presented for a territorial unit of $100 \times 100 \mathrm{~m}$. The reference period is 2011

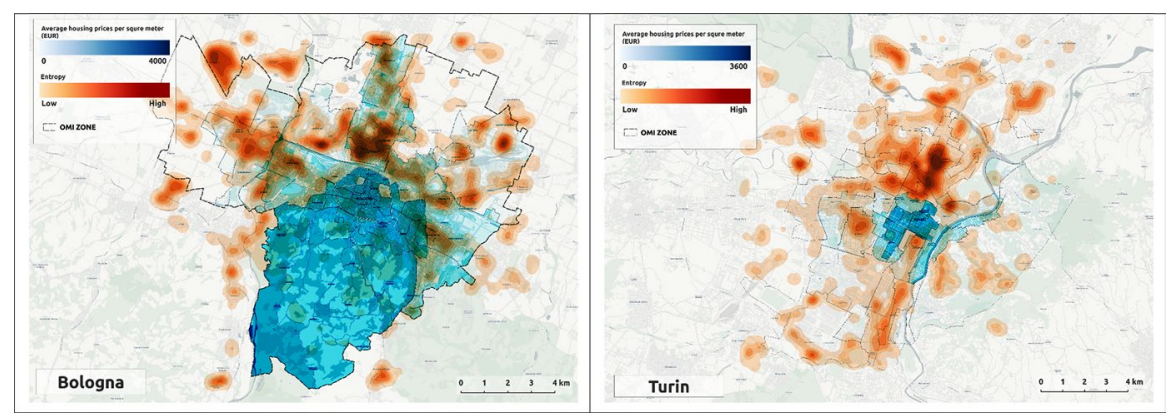

Fig. 7 Average house prices versus Entropy index. Note: House prices correspond to the average price for a square meter of the civilian residential units by OMI micro areas. The entropy index is presented for territorial unit of 100x 100 meters. The reference period is 2011

\section{Appendix 2}

See Table 13 in appendix 2. 


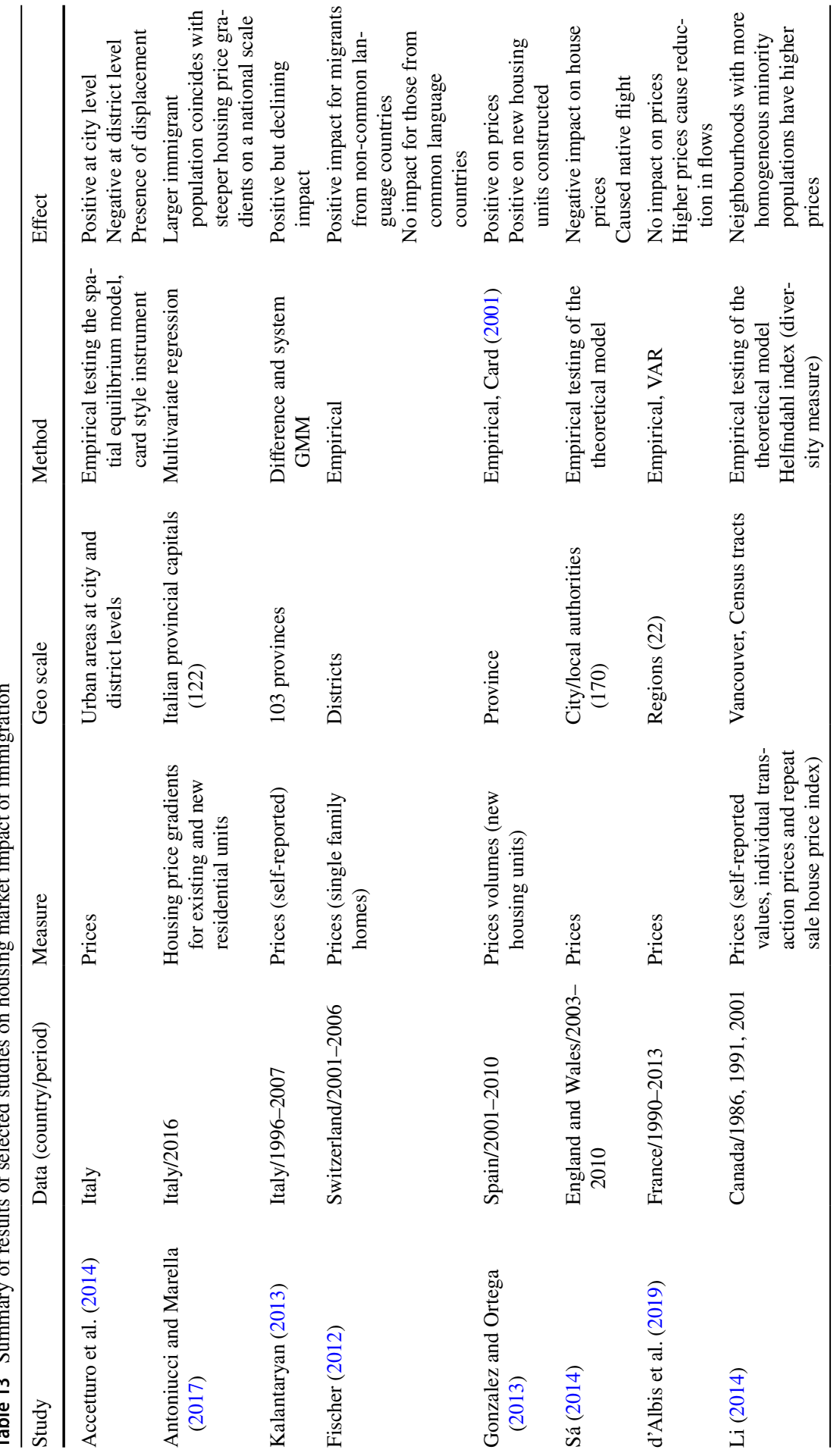




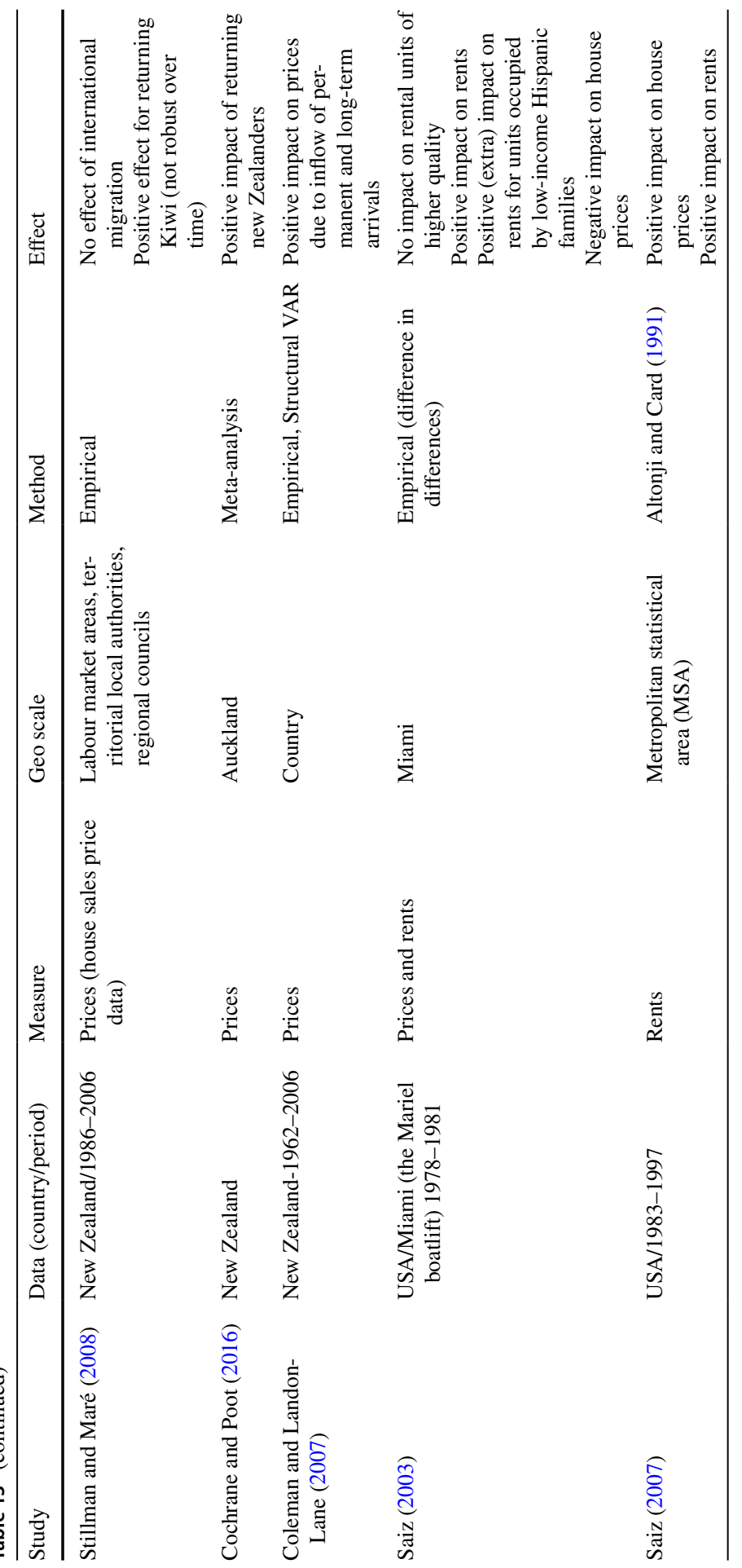




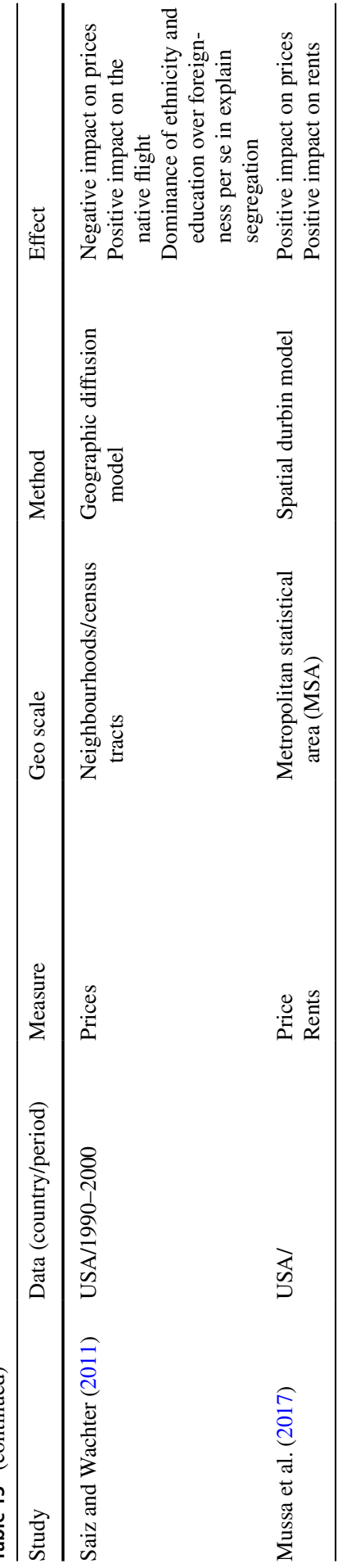




\section{References}

Accetturo, A., Manaresi, F., Mocetti, S., \& Olivieri, E. (2014). Don't stand so close to me: The urban impact of immigration. Regional Science and Urban Economics, 45, 45-56.

Alessandrini, A., Natale, F., Sermi, F., \& Vespe, M. (2017). High resolution map of migrants in the EU (Vol. 199). JRC technical reports EUR 28770 EN.

Altonji, J. G., \& Card, D. (1991). The effects of immigration on the labor market outcomes of lessskilled natives. In Immigration, trade, and the labor market (pp. 201-234). University of Chicago Press, Chicago.

Ambrosini, M. (2013). Immigration in Italy: Between economic acceptance and political rejection. Journal of International Migration and Integration, 14(1), 175-194.

Andersson, R., Bråmå, Å., \& Holmqvist, E. (2010). Counteracting segregation: Swedish policies and experiences. Housing Studies, 25(2), 237-256.

Andersson, E. K., Lyngstad, T. H., \& Sleutjes, B. (2018). Comparing patterns of segregation in NorthWestern Europe: A multiscalar approach. European Journal of Population, 34(2), 151-168.

Antoniucci, V., \& Marella, G. (2017). Immigrants and the city: The relevance of immigration on housing price gradient. Buildings, 7(4), 91.

Arbaci, S. (2007). Ethnic segregation, housing systems and welfare regimes in Europe. European Journal of Housing Policy, 7(4), 401-433.

Arbaci, S. (2008). (Re) viewing ethnic residential segregation in Southern European cities: Housing and urban regimes as mechanisms of marginalisation. Housing Studies, 23(4), 589-613.

Arbaci, S., \& Malheiros, J. (2010). De-segregation, peripheralisation and the social exclusion of immigrants: Southern European cities in the 1990s. Journal of Ethnic and Migration Studies, $36(2), 227-255$.

Barban, N., \& Dalla-Zuanna, G. (2010). A portrait of immigrant children's housing experiences in Italy. Housing Studies, 25(4), 559-584.

Barbulescu, R., \& Beaudonnet, L. (2014). Protecting us, protecting Europe? Public concern about immigration and declining support for European integration in Italy. Perspectives on European Politics and Society, 15(2), 216-237.

Bayer, P., Ferreira, F., \& McMillan, R. (2007). A unified framework for measuring preferences for schools and neighborhoods. Journal of Political Economy, 115(4), 588-638.

Bianchi, M., Buonanno, P., \& Pinotti, P. (2012). Do immigrants cause crime? Journal of the European Economic Association, 10(6), 1318-1347.

Blangiardo, G. C. (2006). Foreigners' Presence in Italy. ISMU: The 11th Italian Report on Migration 2005. V. Cesare, Polimetrica, pp. 35-52.

Blangiardo, G. C. (2007). Foreigner's Presence in Italy. Quantitative Evaluations and Comments. ISMU-The 12th Italian Report on Migration 2006. V. Cesareo, Polimetrica, pp. 41-58.

Blangiardo, G. C. (2008). The centre sampling technique in surveys on foreign migrants. The balance of a multi-year experience. United Nations Statistical Commission and EUROSTAT, Working Paper No 12-29.

Boeri, T., de Philippis, M., Patacchini, E., \& Pellizzari, M. (2012). Moving to segregation: Evidence from 8 Italian cities. Rochester, NY: Social Science Research Network.

Bolt, G., Özüekren, A. S., \& Phillips, D. (2009). Linking integration and residential segregation. Journal of Ethnic and Migration Studies, 36(November), 169-186.

Bonifazi, C., \& Sabatino, D. (2003). Albanian migration to Italy: What official data and survey results can reveal? Journal of Ethnic and Migration Studies, 29(6), 967-995.

Borjas, G. J. (1995). The economic benefits from immigration. Journal of Economics Perspectives, 9(2), 3-22.

Boustan, L. P. (2010). Was postwar suburbanization "white flight"? Evidence from the Black Migration. The Quarterly Journal of Economics, February.

Braakmann, N. (2019). Immigration and the property market: Evidence from England and Wales. Real Estate Economics, 47(2), 509-533.

Brandolini, A., Cannari, L., D’Alessio, G. \& Faiella, I. (2004). Household wealth distribution in Italy. Banca d'Italia, Temi di discussione, No 530.

Card, D. (2001). Immigrant inflows, native outflows, and the local labor market impacts of higher immigration. Journal of Labor Economics, 19(1), 22-64. 
Card, D. (2007). How immigration affects U.S. Cities. Center for Research and Analysis of Migration, CReAM Discussion Paper No 11/07.

Card, D., Mas, A., \& Rothstein, J. (2008). Tipping and the dynamics of segregation. The Quarterly Journal of Economics, 123(1), 177-218.

Censis, Sunia, \& CGIL. (2007). Vivere in Affitto. Piu` case in affitto, piu` mobilita` sociale e territoriale, Roma.

Cochrane, W., \& Poot, J. (2016). Past research on the impact of international migration on house prices: Implications for Auckland.

Cochrane, W., \& Poot, J. (2020). The effects of immigration on local housing. In K. Kourtit, B. Newbold, P. Nijkamp, \& M. Partridge (Eds.), The economic geography of cross-border migration (p. 2020). Berlin: Springer.

Coleman, A., \& Landon-Lane, J. (2007). Housing markets and migration in New Zealand, 1962-2006 (No. DP2007/12). Reserve Bank of New Zealand.

Cortes, P. (2008). The effect of low-skilled immigration on U.S. Prices: Evidence from CPI Data. Journal of Political Economy, 116, 381-422.

Cortese, A. J. (1995). The rise, hegemony, and decline of the Chicago School of Sociology, 1892-1945. Social Science Journal, 32(3), 235-254.

Cuerpo, C., Pontuch, P., \& Kalantaryan, S. (2014). Rental market regulation in the European Union. Economic papers, (515), 1-52. Directorate General Economic and Financial Affairs (DG ECFIN), European Commission.

d'Albis, H., Boubtane, E., \& Coulibaly, D. (2019). International migration and regional housing markets: Evidence from France. International Regional Science Review, 42(2), 147-180.

Daams, M. N., Proietti, P., \& Veneri, P. (2019). The effect of asylum seeker reception centers on nearby house prices: Evidence from The Netherlands. Journal of Housing Economics, 46, 101658.

Del Boca, D., \& Venturini, A. (2005). Italian migration. European migration: What do we know, 153, 303-336.

Di Addario, S. (2002). Italian household tenure choices and housing demand. Mimeo: Banca d'Italia.

Drake, S. C., \& Cayton, H. A. (1945). Black metropolis: A study of negro life in a northern city. Chicago: The University of Chicago Press.

Duncan, O. D., \& Duncan, B. (1957). The negro population of Chicago. Chicago: University of Chicago Press.

Elsinga, M., \& Wassenberg, F. (2014). Social housing in the Netherlands. Social Housing in Europe, 75, 25-40.

Faiella, I. \& Neri, A. (2004). La Ricchezza delle Famiglie Italiane e Americane. Banca d'Italia, Temi di discussione, No 501.

Fasani, F. (2010). The quest for "La Dolce Vita"? Undocumented migration in Italy. In A. Triandafyllidou A. (Ed.), Irregular migration in Europe: Myths and realities, Ashgate.

Filer, R. (1992). The effect of immigrant arrivals on migratory patterns of native workers. In Immigration and the work force: Economic consequences for the United States and source areas (pp. 245-270). University of Chicago Press.

Fischer, A. M. (2012). Immigrant language barriers and house prices. Regional Science and Urban Economics, 42, 389-395. https://doi.org/10.1016/j.regsciurbeco.2011.11.003.

Fravega, E. (2018). L'abitare migrante. Aspetti teorici e prospettive di ricerca. Mondi migranti.

Gavosto, A., Venturini, A., \& Villosio, C. (1999). Do immigrants compete with natives? LABOUR, 13(3), 603-622.

Gonzalez, L., \& Ortega, F. (2013). Immigration and housing booms: Evidence from Spain. Journal of Regional Science, 53(1), 37-59.

Huber, P., \& Oberdabernig, D. A. (2016). Decomposing welfare wedges: An analysis of welfare dependence of immigrants and natives in Europe. Kyklos, 69(1), 82-107.

Jayet, H., Ukrayinchuk, N., \& De Arcangelis, G. (2010). The location of immigrants in Italy: Disentangling networks and local effects. In Annals of economics and statistics/Annales d'Économie et de Statistique, pp. 329-350.

Kalantaryan, S. (2013). Housing market responses to immigration; evidence from Italy. Robert Schuman Centre for Advanced Studies Research Paper (2013/83).

Karsten, S., Felix, C., Ledoux, G., Meijnen, W., Roeleveld, J., \& Van Schooten, E. (2006). Choosing segregation or integration? The extent and effects of ethnic segregation in Dutch cities. Education and Urban Society, 38(2), 228-247. 
Kenneth, F. S., \& Slaughter, M. J. (2001). Labor market competition and individual preferences over migration policy. Review of Economics and Statistics, 83(1), 133-145.

Kovacheva, V., \& Vogel, D. (2009). The size of the irregular foreign resident population in the European Union in 2002, 2005 and 2008: aggregated estimates. Database on Irregular Migration, Working paper (4).

Larkin, M. P., Askarov, Z., Doucouliagos, C., Dubelaar, C., Klona, M., Newton, J., Stanley, T. D., \& Vocino, A. (2018). Do house prices sink or ride the wave of immigration? IZA Discussion Papers No. 11497.

Li, Q. (2014). Ethnic diversity and neighborhood house prices. Regional Science and Urban Economics, 48, 21-38. https://doi.org/10.1016/j.regsciurbeco.2014.04.007.

Malmberg, B., Andersson, E. K., Nielsen, M. M., \& Haandrikman, K. (2018). Residential segregation of European and non-European migrants in Sweden: 1990-2012. European Journal of Population, 34(2), 169-193.

Mayda, A. M. (2006). Who is against immigration? A cross-country investigation of individual attitudes toward immigrants. Review of Economics and Statistics, 88(3), 510-530.

Mollick, S. R. (2016). Life and prospect of bangladeshi migrants to Italy: the Milano Case. Working Paper 17/04. Pavia: Cooperation and Development Network, Master in Cooperation and Development, AY 2015/16.

Mussa, A., Nwaogu, U. G., \& Pozo, S. (2017). Immigration and housing: A spatial econometric analysis. Journal of Housing Economics, 35, 13-25.

Musterd, S. (2005). Social and ethnic segregation in Europe: Levels, causes, and effects. Journal of urban affairs, 27(3), 331-348.

Natale, F., Migali, S., \& Münz, R. (2018a). Many more to come. Migration from and within Africa, Joint Research Centre, Brussels, European Commission.

Natale, F., Scipioni, M., \& Alessandrini, A (2018b). Spatial segregation of migrants in EU cities. In Divided cities: Understanding intra-urban inequalities, OECD Publishing, Paris.

Ong, C. B. (2017). Tipping points in Dutch big city neighbourhoods. Urban studies, 54(4), 1016-1037.

Ottaviano, G. I. \& Peri, G. (2007). The effects of immigration on U.S. wages and rents: A general equilibrium approach. Center for Research and Analysis of Migration, CReAM Discussion Paper No $13 / 07$.

Paasche, E., \& Fangen, K. (2011). Ethnic school segregation: Effects and policies. EUMARGINS Policy Brief, 4.

Paiella, M. (2001). Demand for housing, saving behavior and wealth allocation. Banca d'Italia.

Panichella, N., \& Ambrosini, M. (2018). Between fears, contacts and family dynamics: The anti-immigrant attitudes in Italy. Journal of International Migration and Integration, 19(2), 391-411.

Park, R. E. (1926). The urban community as a spatial pattern and a moral order. In W. E. Burgess (Ed.), The urban community. Chicago: University of Chicago Press.

Park, R. E. (1936). Succession: an ecological concept. American Sociological Review, X(1), 171-179.

Park, R. E. (1955). Society. Glencoe: Free Press.

Park, R. E., \& Burgess, E. W. (1925). The city: Suggestions for the investigation of human behavior in the urban environment. Chicago: The University of Chicago Press.

Pellizzari, M. (2013). The use of welfare by migrants in Italy. International Journal of Manpower, 34(2), 155-166.

Petrillo, A. (2018). La crisi dell'abitare migrante in Italia. Una prospettiva storica. Sociologia urbana e rurale.

Phillips, D. (2010). Minority ethnic segregation, integration and citizenship: A European perspective. Journal of Ethnic and Migration studies, 36(2), 209-225.

Ponzo, I. (2009). La casa lontano da casa, romeni e marocchini a confronto. Serie FIERI/3, Roma.

Pozzo, A. M. (2002). I numeri della casa.La casa in Europa, Le condizioni. Federcasa, Roma.

Sá, F. (2014). Immigration and house prices in the UK. The Economic Journal, 125(587), 1393-1424.

Saiz, A. (2003). Room in the kitchen for the melting pot: Immigration and rental prices. Review of Economics and Statistics, 85, 502-521.

Saiz, A. (2007). Immigration and housing rents in American cities. Journal of Urban Economics, 61, 345-371. https://doi.org/10.1016/j.jue.2006.07.004.

Saiz, A., \& Wachter, S. (2011). Immigration and the neighborhood. American Economic Journal: Economic Policy, 3, 169-188.

Sandoval, J. O. (2000). The multicultural metropolis: Neighborhood diversity and segregation patterns in the city of Chicago, 1990-2000 (Doctoral dissertation, Northwestern University). 
Scanlon, K., Fernández Arrigoitia, M., \& Whitehead, C. M. (2015). Social housing in Europe. European Policy Analysis, 17, 1-12.

Schelling, T. (1971). Dynamic models of segregation. Journal of Mathematical Sociology, 1, 143-186.

Schelling, T. C. (1978). Sorting and mixing. Micromotives and macrobehavior.

Shannon, C. (1948). A mathematical theory of communication. Bell entity Technical Journal, 27(3), 379-423.

Skifter Andersen, H., Andersson, R., Wessel, T., \& Vilkama, K. (2016). The impact of housing policies and housing markets on ethnic spatial segregation: Comparing the capital cities of four Nordic welfare states. International Journal of Housing Policy, 16(1), 1-30.

Staffolani, S., \& Valentini, E. (2010). Does immigration raise blue and white collar wages of natives? The case of Italy. Labour, 24(3), 295-310.

Stillman, S., \& Maré, D. C. (2008). Housing markets and migration: Evidence from New Zealand. Available at SSRN 1146724.

Sunia. (2009). Gli immigrant e la casa. Roma.

Venturini, A. \& Villosio, C. (2004). Labour market effects of immigration: an empirical analysis based on Italian data, International Migration Papers, 69.

Yinger, J. (1985). Ethnicity. Annual Review of Sociology, 11, 151-180.

Yinger, J. (1995). Closed doors, opportunities lost: the continuing costs of housing discrimination. New York: Russell Sage Foundation.

Zhu, J., Brown, S., \& Pryce, G. B. (2018). Immigration and house prices under various regional economic structures in England and Wales. Urban Studies, Sage.

Publisher's Note Springer Nature remains neutral with regard to jurisdictional claims in published maps and institutional affiliations. 